\title{
Bucillamine prevents cisplatin-induced ototoxicity through induction of glutathione and antioxidant genes
}

\author{
Se-Jin Kim ${ }^{1,5}$, Joon Ho Hur ${ }^{2,5}$, Channy Park ${ }^{3}$, Hyung-Jin Kim ${ }^{1}$, Gi-Su Oh ${ }^{1}$, Joon No Lee ${ }^{1}$, Su-Jin Yoo ${ }^{2}$, \\ Seong-Kyu Choe ${ }^{1}$, Hong-Seob So ${ }^{1,4}$, David J Lim ${ }^{3}$, Sung K Moon ${ }^{3}$ and Raekil Park ${ }^{1,4}$
}

Bucillamine is used for the treatment of rheumatoid arthritis. This study investigated the protective effects of bucillamine against cisplatin-induced damage in auditory cells, the organ of Corti from postnatal rats (P2) and adult Balb/C mice. Cisplatin increases the catalytic activity of caspase- 3 and caspase- 8 proteases and the production of free radicals, which were significantly suppressed by pretreatment with bucillamine. Bucillamine induces the intranuclear translocation of Nrf2 and thereby increases the expression of $\gamma$-glutamylcysteine synthetase $(\gamma$-GCS) and glutathione synthetase (GSS), which further induces intracellular antioxidant glutathione (GSH), heme oxygenase 1 (HO-1) and superoxide dismutase 2 (SOD2). However, knockdown studies of HO-1 and SOD2 suggest that the protective effect of bucillamine against cisplatin is independent of the enzymatic activity of HO-1 and SOD. Furthermore, pretreatment with bucillamine protects sensory hair cells on organ of Corti explants from cisplatin-induced cytotoxicity concomitantly with inhibition of caspase-3 activation. The auditory-brainstem-evoked response of cisplatin-injected mice shows marked increases in hearing threshold shifts, which was markedly suppressed by pretreatment with bucillamine in vivo. Taken together, bucillamine protects sensory hair cells from cisplatin through a scavenging effect on itself, as well as the induction of intracellular GSH.

Experimental \& Molecular Medicine (2015) 47, e142; doi:10.1038/emm.2014.112; published online 20 February 2015

\section{INTRODUCTION}

Cisplatin is a commonly used platinum-containing anticancer drug for various solid tumors, but its clinical application has been limited because of the onset of severe side effects such as peripheral and central neuropathies, renal insufficiency and sensorineural hearing loss. ${ }^{1-3}$ The histopathology of cisplatin ototoxicity studied in animals ${ }^{4,5}$ and humans ${ }^{6}$ shows that cisplatin primarily damages the outer hair cells (OHCs) of the organ of Corti in the inner ear, ${ }^{7}$ with gradual progress from the basal area to the apex in the cochlear turn. ${ }^{8}$

The cytotoxic effects of cisplatin are due to the formation of DNA adducts that lead to aberrant genetic transcription and DNA duplication, cell cycle arrest and apoptosis. ${ }^{9} 10$ They are also due to the accumulation of reactive oxygen species (ROS), reactive nitrogen species and free radicals, which are often involved in functional damage to various tissues, including the structures within the inner ear. ${ }^{11-13}$ In cisplatin-induced ototoxicity, ROS are formed as a consequence of antioxidant depletion and interference with the antioxidant defense system of the cochlea. ${ }^{3,14}$ Excessive ROS can react with a variety of cellular components, such as DNA, proteins and unsaturated lipids, leading to chemical modifications and metabolic and structural alterations, which may result in cell death. ${ }^{15}$ The active form of cell death is characterized by morphological changes such as cell shrinkage, chromatin condensation and DNA fragmentation. Both caspase- 8 and caspase- 9 participate in a cascade that culminates in the activation of caspase-3, which then cleaves several substrates, resulting in chromosomal DNA fragmentation and the cellular morphological changes characteristic of apoptosis. ${ }^{16}$ Several reports have recently demonstrated that cisplatin ototoxicity could be alleviated by treatment with a chemoprotectant, such as diethyldithiocarbamate, ebselen, flunarizine, sodium thiosulfate, glutathione (GSH) or other sulfur-containing compounds. ${ }^{3,17-21}$ Accordingly, treatment with a chemoprotectant has been shown to

\footnotetext{
${ }^{1}$ Department of Microbiology, Center for Metabolic Function Regulation (CMFR), Wonkwang University College of Medicine, Iksan, Jeonbuk, Korea; ${ }^{2}$ Emergency medicine, Wonkwang University, College of Medicine, Iksan, Jeonbuk, Korea; ${ }^{3}$ Department of Head \& Neck Surgery, David Geffen School of Medicine, University of California Los Angeles, Los Angeles, CA, USA and ${ }^{4}$ BK21Plus Program \& Department of Smart Life-Care Convergence, Wonkwang University College of Medicine, Iksan, Jeonbuk, Korea

5These authors contributed equally to this work.

Correspondence: Professor R Park, Department of Microbiology, Center for Metabolic Function Regulation (CMFR), Wonkwang University College of Medicine, 344-2 Shinyong-dong, Iksan, Jeonbuk 570-749, Korea.

E-mail: rkpark@wku.ac.kr
}

Received 16 October 2014; revised 10 November 2014; accepted 14 November 2014 
increase a number of important antioxidant enzymes in cochlear tissues, including catalase, GSH peroxidase, GSH reductase, GSH S-transferase, $\gamma$-glutamylcysteine synthetase $\left(\gamma\right.$-GCS) and superoxide dismutase (SOD). ${ }^{3,14,22,23}$

Oxidative stress is known to induce the expression of GSHsynthesizing enzymes that act through the antioxidant response element and the transcription factor Nrf2. ${ }^{24}$ Transcription factor Nrf2 dissociates from the Keap1-Nrf2 complex and then translocates into the nucleus, where it associates with antioxidant response element to enhance the expression of phase II genes and detoxifying genes, such as catalase, GST, GPx, GR, $\gamma$-GSC (composed of the catalytic (GCLC) and regulatory (GCLM) subunits) and heme oxygenase-1 (HO-1). ${ }^{25-27}$ These enzymes play important roles in protecting cells from oxidative stress imposed by free radicals. GSH is synthesized in the cytosol of all mammalian cells in a tightly regulated manner. The major determinants of GSH synthesis are the availability of cysteine, the sulfur amino acid precursor and the involvement of two enzymatic reactions catalyzed by the rate-limiting enzymes $\gamma$-GCS and GSS. ${ }^{28}$

Bucillamine (N-(2-mercapto-2-methylpropionyl)-L-cysteine) is a low molecular weight thiol donor capable of rapidly entering cells, and it is used to treat rheumatoid arthritis. ${ }^{29}$ Bucillamine can also directly scavenge peroxides and is shown to be 4 -fold more effective than $N$-acetylcysteine (NAC) in preventing ischemia-reperfusion injury from in vitro studies ${ }^{30}$ and 16 -fold more effective from in vivo studies. ${ }^{31}$ In experimental studies, bucillamine, like the cysteine derivative NAC, inhibited liver ischemia-reperfusion injury and raised the survival rate after transplant by increasing GSH levels in the liver and decreasing oxidized GSH levels in both the liver and blood. ${ }^{32}$ In recent studies using murine Hepa 1-6 and human HepG2 hepatoma cells, the mechanisms of action of bucillamine have been mainly described as donating thiol groups to GSH and significantly increasing the GSH content by two to threefold, as well as inducing the expression of the $\gamma$-GCS catalytic subunit (GCLC), the rate-limiting enzyme of GSH biosynthesis and the multidrug-resistance-associated protein (Mrp2), which mediates the excretion of GSH. ${ }^{33}$ However, the molecular mechanism of bucillamine to mediate the beneficial effect has not been fully elucidated.

In this study, we investigated for the first time the antioxidant and cytoprotective roles of bucillamine against cisplatininduced cytotoxicity in auditory cells in vitro and organ of Corti explants ex vivo. Furthermore, we also investigated in vivo effects of bucillamine on auditory-brainstem-evoked response $(\mathrm{ABR})$ threshold changes in cisplatin-treated $\mathrm{Balb} / \mathrm{C}$ mice.

\section{MATERIALS AND METHODS}

\section{Chemicals}

Cisplatin and 3-(4,5-dimethylthiazol-2-yl)-2, 5-diphenyl-tetrazolium bromide (MTT) were purchased from Sigma Chemical Co (St Louis, MO, USA). Bucillamine was a generous gift from Kuhnil Pharmaceutical Co. (Seoul, Korea). Genomic DNA purification kits were obtained from Promega (Madison, WI, USA). Plastic culture wares were purchased from Falcon, Inc. (Becton Dickinson Biotech, Lincoln,
IL, USA). Dulbecco's modified essential medium (DMEM), fetal bovine serum (FBS) and other tissue culture reagents were purchased from Life Technologies, Inc. (Gaithersburg, MD, USA). Various antibodies, including anti-GCLM, anti-GCLC, anti-GSS, anti-Nrf2, anti-SOD1, anti-SOD2 and anti- $\beta$-actin antibodies were obtained from Santa Cruz Biotechnology (Santa Cruz, CA, USA). The anti-HO-1 monoclonal antibody was purchased from Stressgen (Ann Arbor, MI, USA). The active form of anti-caspase-3 was purchased from Abcam (Cambridge, UK).

\section{Animals}

Twenty healthy Balb/C male mice (weight $20 \pm 1 \mathrm{~g}$ ) were used in this study, and their hearing ability was confirmed to be within the normal range by ABR measurements. Animals were randomly divided into four groups - control mice ( $0.9 \%$ saline solution), mice injected with bucillamine ( $100 \mathrm{mg} \mathrm{kg}^{-1}$ per day) alone for 4 days, mice injected with cisplatin ( $4 \mathrm{mg} \mathrm{kg}^{-1}$ per day) alone for 4 days, and mice injected with bucillamine and cisplatin-and were used to carry out ABR studies after 3 days following the cisplatin injection. Stock solutions of bucillamine $\left(5 \mathrm{mg} \mathrm{ml}^{-1}\right)$ were prepared in normal saline $(\mathrm{pH} 7.4)$ with equimolar $\mathrm{NaOH}$ and sterilized using a $0.22-\mu \mathrm{m}$ syringe filter. The mice were subsequently injected with bucillamine twice a day (100 $\mathrm{mg} \mathrm{kg}^{-1}$ per day, intraperitoneally (i.p.)); control mice received saline solution. This study was reviewed by the Committee for Ethics in Animal Experiments of the Wonkwang University and carried out under Korean law and the Guidelines for Animal Experiments.

\section{Cell culture and viability assays}

HEI-OC1 auditory cells were maintained in high-glucose DMEM containing $10 \%$ FBS for characterization. For the experiments described below, HEI-OC1 cells were cultured under the following permissive conditions: $33^{\circ} \mathrm{C}, 5 \% \mathrm{CO}_{2}$ in DMEM supplemented with $10 \%$ FBS. Cells $\left(5 \times 10^{4}\right.$ per well in 24 -well plates $)$ were incubated with various concentrations of bucillamine $(0.25 \sim 4 \mathrm{~mm})$ and cisplatin $(20 \mu \mathrm{M})$ for $30 \mathrm{~h}$. To determine cell viability, MTT $\left(0.5 \mathrm{mg} \mathrm{ml}^{-1}\right.$ phosphate-buffered saline (PBS)) solution was added to the cell culture media $(1 / 100, \mathrm{v} / \mathrm{v})$ for $4 \mathrm{~h}$ and washed with PBS ( $\mathrm{pH} 7.4)$. Dimethyl sulfoxide was added to each well to solubilize the formazan crystals formed in viable cells. The optical density of each culture well was measured by using a microtiter plate reader (Molecular Devices Co., Sunnyvale, CA, USA) at $590 \mathrm{~nm}$. The optical density of control cells was taken as $100 \%$ viability.

\section{DAPI staining of nuclei}

The nuclei of HEI-OC1 cells were stained with the chromatin dye 4'-6-diamidino-2-phenylindole (DAPI). Cells were fixed with 3.7\% paraformaldehyde for $10 \mathrm{~min}$ at room temperature, washed twice with PBS and then incubated with $10 \mu \mathrm{M}$ DAPI in PBS at room temperature for $30 \mathrm{~min}$. After three washes, cells were observed under a fluorescence microscope (IX71, Olympus, Tokyo, Japan).

\section{Genomic DNA preparation and electrophoresis}

Genomic DNA was isolated using the Wizard genomic DNA purification kit (Promega) and purified by serial ethanol precipitations. Five micrograms of isolated genomic DNA were subjected to $1.5 \%$ agarose gel electrophoresis at $50 \mathrm{~V}$ for $3 \mathrm{~h}$. DNA was visualized under UV light following staining with ethidium bromide. 


\section{Colorimetric caspase- 3 and caspase- 8 activity assay}

Colorimetric assay kits (R\&D Systems, Inc., Minneapolis, MN, USA) were used to measure the enzyme activities of caspase- 3 and caspase- 8 according to the manufacturer's instructions. After $24 \mathrm{~h}$ treatment with cisplatin in the presence or absence of bucillamine, the medium was gently removed and discarded, while the cell pellet was lysed by the addition of the lysis buffer. The cell lysates were incubated on ice for $10 \mathrm{~min}$ and centrifuged at $10000 \times g$ for $1 \mathrm{~min}$ at $4{ }^{\circ} \mathrm{C}$. The supernatant was then transferred to a new tube to determine caspase activity. Extracts $(50 \mu \mathrm{l})$ from cells treated with cisplatin in the presence or absence of bucillamine were added to $50 \mu \mathrm{l}$ of reaction buffer and $5 \mu \mathrm{l}$ of caspase-3 (DEVD-pNA) or caspase-8 (IETD-pNA) colorimetric substrate. Each mixture was placed in wells of a 96-well plate and incubated for $1 \mathrm{~h}$ at $37^{\circ} \mathrm{C}$. Absorbance at $405 \mathrm{~nm}$ was measured using a microtiter plate reader (Molecular Devices Co., Sunnyvale, CA, USA). Caspase activity was normalized to micrograms of protein using a Bio-Rad protein assay kit (Bio-Rad Co., Hercules, CA, USA).

\section{Preparation of cytosolic and nuclear fractions}

Cells were washed with ice-cold PBS, scraped and centrifuged at $1000 \times g$ for $5 \mathrm{~min}$ at $4{ }^{\circ} \mathrm{C}$. The cell pellet was resuspended in $200 \mu \mathrm{l}$ of lysis buffer (10 mM HEPES ( $\mathrm{pH} 7.9$ ), $1.5 \mathrm{~mm} \mathrm{MgCl}_{2}, 0.5 \mathrm{~mm}$ dithiothreitol and $0.5 \mathrm{~mm}$ phenylmethylsulfonyl fluoride) and incubated on ice for $15 \mathrm{~min}$. At the end of the incubation, $10 \mu \mathrm{l}$ of $10 \% \mathrm{NP}-40$ were added and the tube was vortexed for $10 \mathrm{~s}$. After centrifugation at $13000 \times g$ for $1 \mathrm{~min}$ at $4{ }^{\circ} \mathrm{C}$, the supernatant (cytosolic extracts) was collected and stored at $-80^{\circ} \mathrm{C}$, and the pellet was further processed to obtain a nuclear extract. The pellet was resuspended in extraction buffer ( 5 mM HEPES ( $\mathrm{pH} 7.9$ ), $1.5 \mathrm{~mm} \mathrm{MgCl}, 0.5 \mathrm{~mm}$ phenylmethylsulfonyl fluoride, $0.2 \mathrm{~mm}$ EDTA, $0.5 \mathrm{~mm}$ dithiothreitol and $25 \%$ glycerol $(\mathrm{vol} / \mathrm{vol})$ ) and incubated for $30 \mathrm{~min}$ at $4{ }^{\circ} \mathrm{C}$. The supernatant (nuclear extracts) was aliquoted and stored at $-80{ }^{\circ} \mathrm{C}$ until used for western blot analysis. The protein concentration was determined by the Lowry method.

\section{Western blotting}

Cell extracts were separated by $10 \%$ SDS-PAGE under reducing conditions and transferred to a nitrocellulose membrane. Nonspecific proteins were blocked with $5 \%$ skim milk in TBS-T $(25 \mathrm{~mm}$ Tris ( $\mathrm{pH} 7.6), 138 \mathrm{~mm} \mathrm{NaCl}$ and $0.05 \%$ Tween-20) for $1 \mathrm{~h}$ and probed with primary antibodies (diluted 1:1000-1:5000). After a series of washes, the membrane was incubated with secondary antibody (diluted 1:2000-1:10000) conjugated with horseradish peroxidase. The immunoreactive signal was detected using an enhanced chemiluminescent detection system. The active form of caspase- 3 antibody (1:1000 dilution; Abcam) was used to recognize the large fragment of cleaved caspase- $3(17 \mathrm{kDa})$. The protein concentration was estimated according to the protocol from Bio-Rad Laboratories, Inc., using $1 \mathrm{mg} \mathrm{ml}^{-1}$ bovine serum albumin as the standard.

\section{Measurement of intracellular ROS and nitric oxide levels}

HEI-OC1 cells were cultured overnight and then treated with $20 \mu \mathrm{M}$ cisplatin in the presence or absence of bucillamine for $24 \mathrm{~h}$. Intracellular ROS levels were measured using the fluorescent dye 2',7'-dichlorofluorescein diacetate (DCF-DA, Eastman Kodak, Rochester, NY, USA). In the presence of an oxidant, DCF-DA is converted into the highly fluorescent DCF. For the ROS assay, the cells were treated with $10 \mu \mathrm{M}$ DCF-DA and were further incubated for $1 \mathrm{~h}$ at $37^{\circ} \mathrm{C}$. Intracellular nitric oxide (NO) production by HEI-OC1 cells was assessed by measuring the fluorescence of 4-amino-5-methylamino$2^{\prime}, 7^{\prime}$-difluorofluorescein, a specific NO probe (Molecular Probes, Inc.,
Eugene, OR, USA). 4-Amino-5-methylamino-2',7'-difluorofluorescein is a cell-permeable, NO-sensitive dye that is virtually nonfluorescent until it reacts with $\mathrm{NO}$ to form a fluorescent benzotriazole. For the NO assay, the cells were treated with $10 \mu \mathrm{M}$ DAF-FA and were further incubated for $1 \mathrm{~h}$ at $37^{\circ} \mathrm{C}$. The cells were rinsed with PBS and detected through flow cytometric analysis. Fluorescence intensity was measured using a BD FACSCalibur Flow Cytometer System (BD Biosciences, San Jose, CA, USA). For each analysis, 20000 events were collected and analyzed using FL1 (DCF-DA and 4-amino-5-methylamino-2', $7^{\prime}$-difluorofluorescein) channel. Data were analyzed using BD Cell Quest Software (BD Biosciences).

\section{Measurement of reduced GSH contents}

Intracellular GSH content was measured by using a Glutathione Assay Kit (Sigma) according to the manufacturer's instruction with minor modifications. To analyze the effect of bucillamine on intracellular GSH concentration, HEI-OC1 cells seeded in 100-mm dishes were treated with $20 \mu \mathrm{M}$ cisplatin in the presence or absence of $2 \mathrm{~mm}$ bucillamine. After experimental treatment, cells were harvested and washed with ice-cold PBS $\left(0.24 \mathrm{gl}^{-1} \mathrm{KH}_{2} \mathrm{PO}_{4}, 1.44 \mathrm{gl}^{-1} \mathrm{Na}_{2} \mathrm{HPO}_{4}\right.$, $0.2 \mathrm{gl}^{-1} \mathrm{KCl}$ and $8.0 \mathrm{gl}^{-1} \mathrm{NaCl}(\mathrm{pH} 7.4)$ ). Cells were centrifuged at $600 \times g$ to obtain a cell pellet, and the supernatant was removed. Cells were then suspended in $0.2 \mathrm{ml}$ of $0.1 \mathrm{M}$ potassium phosphate buffers (pH 7.0) containing $1 \mathrm{~mm}$ EDTA. The cell suspension was sonicated to obtain the cell homogenate; the resulting homogenate $(0.2 \mathrm{ml}$ lysate) was transferred to microcentrifuge tubes, except for a small portion that was saved for protein quantification. An equal volume of $5 \%$ sulfosalicylic acid was added to the cell extract $(0.2 \mathrm{ml})$, and the precipitated proteins were sedimented by centrifugation at $10000 \times g$ for $10 \mathrm{~min}$ at $4{ }^{\circ} \mathrm{C}$. The volume of the supernatant was measured, and the original volume for total GSH was used according to the manufacturer's instruction. For microplate reader determination, $10 \mu \mathrm{l}$ of the cell extract supernatant or of the standard GSH solution was mixed with $150 \mu \mathrm{l}$ of the working mixture, and then $50 \mu \mathrm{l}$ of $0.16 \mathrm{mg} \mathrm{ml}^{-1} \mathrm{NADPH}$ solution was added with a multichannel pipette. The final concentration of the components in the reaction mixture was $95 \mathrm{~mm}$ potassium phosphate buffer $(\mathrm{pH} 7.0), 0.95$ mм EDTA, 0.038 $\mathrm{mg} \mathrm{ml}^{-1} \mathrm{NADPH}, 0.031 \mathrm{mg} / \mathrm{MlDTNB}$ (5,5'-dithio-bis(2-nitrobenzoic acid)), 0.115 units $\mathrm{ml}^{-1} \mathrm{GSH}$ reductase and $0.24 \%$ 5-sulfosalicylic acid. The total GSH content was expressed as $\mathrm{nmol} \mathrm{mg}^{-1}$ protein. Values were represented as the mean (s.d.) of triplicate samples.

\section{Analysis of mRNA levels by semi-quantitative reverse transcription-PCR}

Cells were plated on $60-\mathrm{mm}$ dishes to a density of $1 \times 10^{5}$, and total cellular RNA was extracted using TRIzol reagent (Invitrogen, Carlsbad, CA, USA) according to the manufacturer's protocol. Equal amounts $(1 \mu \mathrm{g})$ of total RNA were treated with reverse transcriptase (Promega, Madison, WI, USA) in the presence of 20 units of RNasin (Promega). Amplification of cDNA was performed in $20 \mu \mathrm{l}$ reactions containing $10 \mu \mathrm{l}$ of $2 \times$ Taq Premix I (SolGent Co., Daejeon, Korea) and $2 \mu \mathrm{l}$ of each primer $(5 \mathrm{pmol})$. To ensure that equal amounts of cDNA were added to the PCRs, an internal standard was amplified using the $\beta$-actin gene oligonucleotides (F5'-GTGGGCCGCTCTAGGCACCAA $-3^{\prime}$ and R5'-CTCTTTGATGTCACGCACGATTTC-3'). Transcription factor Nrf2 was amplified using synthetic primers (F5'-AGCTC TCTGGAGGCAGCCATGAC-3' and R5'-GACTCCACGGAGTG CTCTGG-3'). GSH redox system-related genes and phase II antioxidant genes were amplified using synthetic primers as follows: GSS, F5'-CCCGCCTCCGAGCCACCTT-3' and R5'-CCACTCCTGCCGC 
CACACCT-3'; GCLC, F5'-ACAAGCACCCCCGCTTCGGT-3' and R5'-CTCCAGGCCTCTCTCCTCCC-3'; GCLM, F5'-ACCTGGCCTC CTGCTGTGTG-3' and R5'-GGTCGGTGAGCTGTGGGTGT-3'. The amplified PCR products were resolved by $1.0 \%$ agarose gel electrophoresis, stained with ethidium bromide, and visualized under UV.

\section{Quantitative real-time PCR}

First-strand cDNAs obtained from total RNAs were used for quantitative real-time PCR. Quantitative real-time PCR was performed with Lightcycler Nano (Roche, Indianapolis, IN, USA) using the FastStart Essential DNA Green Master (Roche Diagnostics, GmbH, Mannheim, Germany). The primers used were as follows: GAPDH, F5'-TGGT CCCGTAGACAAAATGG- $3^{\prime}$ and R5'-TTGAGGTCAATGAAGGGG TC-3'; HO-1, F5'-ACAACCAGTGAGTGGAGCCT-3' and R5'-TCA AGGCCTCAGACAAATCC-3'; Nrf2, F5'-CCTCTGCTGCAAGTAG CCTC-3' and R5'-TGCCTCCAAAGGATGTCAAT-3'; GSS, F5'-GAA GCAGCTCGAAGAACTGG-3' and R' ${ }^{\prime}$-AGCACTGGGTACTGGTG AGG-3'; GCLC, F5'-CTGCACATCTACCACGCAGT-3' and R5'-GTC TCAAGAACATCGCCTCC-3'; GCLM, F5'-CGGGAACCTGCTCAAC TG-3' $3^{\prime}$ and R5'-CCAAAACATCTGGAAACTCCC-3'; SOD1, F5'-AC CATCCACTTCGAGCAGAA-3' and R5'-AAAATGAGGTCCTGCAC TGG-3'; SOD2, F5'-AACTCAGGTCGCTCTTCAGC-3' and R5'-GCT TGATAGCCTCCAGCAAC-3'. GAPDH expression was used to normalize mRNA levels. The evaluation of relative mRNA levels among the treatment groups was carried out using the $\Delta \Delta \mathrm{CT}$ method. Data are presented as relative fold changes compared with the control group.

\section{Transfection of small interference RNA in HEI-OC1 cells} Predesigned small interference RNAs (siRNAs) against mouse HO-1 (sc-35555), SOD2 (sc-416560) and control siRNA (sc-37007) were purchased from Santa Cruz Biotechnology. The sense strands of siRNAs against HO-1 and SOD2 are a pool of three target-specific siRNAs designed for known gene expression. Cells were transfected with double-stranded siRNAs $\left(0.5 \mu \mathrm{g} \mathrm{ml}^{-1}\right)$ in antibiotic- and serumfree medium for $6 \mathrm{~h}$ by using the X-tremeGENE siRNA transfection reagent according to the protocol provided by manufacturer (Roche Applied Sciences, Indianapolis, IN, USA) and recovered by the addition of fresh medium containing 10\% FBS for $12 \mathrm{~h}$. Next, these cells were treated with $20 \mu \mathrm{M}$ cisplatin in the presence or absence of bucillamine for $24 \mathrm{~h}$. The expression of HO-1 and SOD2 was confirmed by western blot analysis (anti-HO-1 and anti-SOD2 antibodies) and reverse transcription-PCR (RT-PCR) (HO-1 and SOD-2 primer). Blots were reprobed with a goat anti- $\beta$-actin antibody for a protein loading control, and RT-PCR was performed with $\beta$-actin primer as a control.

\section{Organotypic cultures of organ of Corti explants}

Sprague-Dawley rats were killed on postnatal day 2 (P2), and the cochlea were carefully dissected. The stria vascularis and the spiral ligament were dissected away, leaving the organ of Corti. For further study, the organ of Corti was dissected into three regions of the apical, middle and basal turns. Cochlear explants were treated with DMEM containing glucose $\left(4.5 \mathrm{gl}^{-1}\right)$ and $10 \%$ FBS during the stationary phase of cell growth at $12 \mathrm{~h}$ post dissection. Cochlear explants were pretreated with $2 \mathrm{~mm}$ bucillamine for $1 \mathrm{~h}$ before the addition of $30 \mu \mathrm{m}$ cisplatin. Following the addition of cisplatin and $2 \mathrm{~mm}$ bucillamine or $30 \mu \mathrm{M}$ cisplatin-only treatments, the cells were incubated for $30 \mathrm{~h}$ at $37^{\circ} \mathrm{C}, 5 \% \mathrm{CO}_{2}$. The control group, maintained with serum containing DMEM only, was cultured concurrently with the experimental groups.
At the end of the experiment, the cultures were prepared for histological analysis. Organotypic cultures of the organ of Corti were fixed in 4\% paraformaldehyde in PBS at room temperature for $15 \mathrm{~min}$. The specimens were rinsed with PBS, incubated in $0.25 \%$ Triton X-100 for $2 \mathrm{~min}$ and immersed in tetramethylrhodamine isothiocyanate-labeled phalloidin (Sigma, 1:100 diluted) in PBS for $20 \mathrm{~min}$. After rinsing three times with PBS, the specimens were examined under a fluorescence microscope with appropriate filters for tetramethylrhodamine isothiocyanate (excitation $540-545 \mathrm{~nm}$, emission $570-573 \mathrm{~nm})$.

\section{Auditory-brainstem-evoked response}

ABR measurement was performed with TDT system II (Tucker Davies Technologies, Gainesville, FL, USA) and standard modular system using TDT Bio-Sigsoftware. Before ABR measurement, the animals were anesthetized intramuscularly with a mixture of xylazine $\left(10 \mathrm{mg} \mathrm{kg}^{-1}\right)$ and ketamine $\left(40 \mathrm{mg} \mathrm{kg}^{-1}\right)$ and placed in an electrically shielded, double-walled radiofrequency-shielded sound booth. An earphone (Etymotic ER-2, Etymotic Research, Elk Grove Village, IL, USA) was placed directly into the ear canal. An active electrode lead was placed at the vertex, the reference electrode at the test ear and the ground electrode below the neck muscle. Auditory stimuli were recorded in response to $100-\mu$ s clicks and 10 -ms tone burst with a rise/fall time of 1 msat 4,8,16 and $32 \mathrm{kHz}$. The sound intensity was progressively decreased in $10-\mathrm{dB}$ steps and $5-\mathrm{dB}$ steps (click). The ABR threshold was defined as the lowest stimulus intensity that produced a replicable waveform response. Weight loss was monitored daily for 8 days after all reagent (cisplatin, bucillamine, saline) treatments, and mice were supplied with $0.6 \mathrm{ml}$ saline solution (i.p. injection, twice a day) to prevent death from dehydration.

\section{Statistical analysis}

Each experiment was performed at least three times, and all values are represented as the means (s.d.) of triplicates. One-way analysis of variance was used to analyze the statistical significance of the results. All analyses were performed using the Origin Pro 7.5 statistical software program. $P$ values less than 0.05 were considered statistically significant.

\section{RESULTS}

\section{Bucillamine protects $\mathrm{HEI}-\mathrm{OC1}$ cells from cisplatin-induced apoptotic death.}

To investigate effects of bucillamine on cisplatin-induced cytotoxicity, we first analyzed whether bucillamine affects the viability of HEI-OC1 cells by using MTT reduction assay. Bucillamine alone at various concentrations $(0.25-4 \mathrm{~mm})$ had no significant effect on cell viability (data not shown), whereas treatment with $20 \mu \mathrm{M}$ cisplatin significantly decreased cell viability compared with control HEI-OC1 cells maintained with medium only (Figure 1a). We further found that pretreatment with bucillamine followed by cisplatin $(20 \mu \mathrm{M})$ prevented the cytotoxicity caused by cisplatin in a dosedependent manner. To determine whether cisplatin-induced reduction in cell viability is due to apoptosis, we examined the internucleosomal cleavage of DNA in HEI-OC1 cells after treatment with cisplatin in the presence or absence of bucillamine (Figure 1b). Treatment with cisplatin resulted in DNA fragmentation, visible as a ladder pattern characteristic of 
a

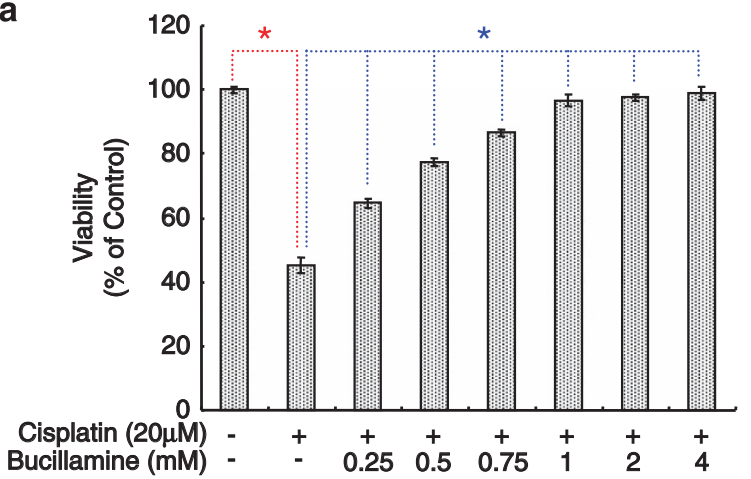

b

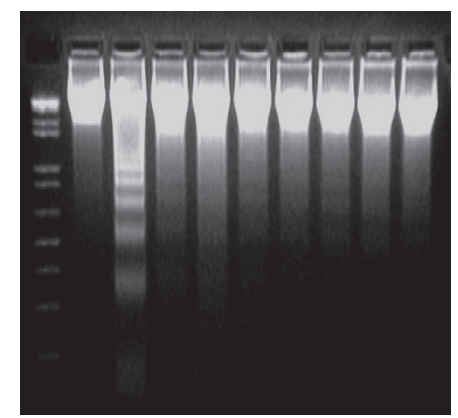

Cisplatin $(20 \mu \mathrm{M})-++++++\quad-$ Bucillamine (mM) - $\quad-0.250 .50 .751212$
C

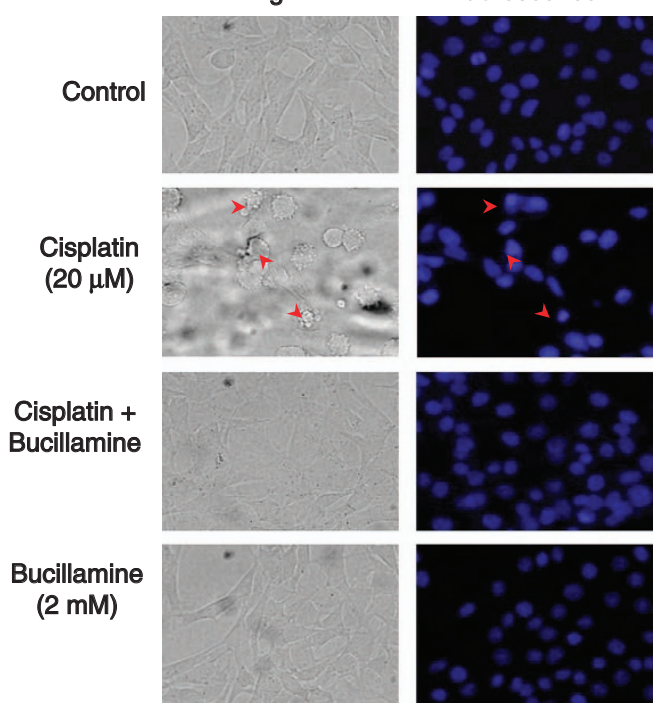

d
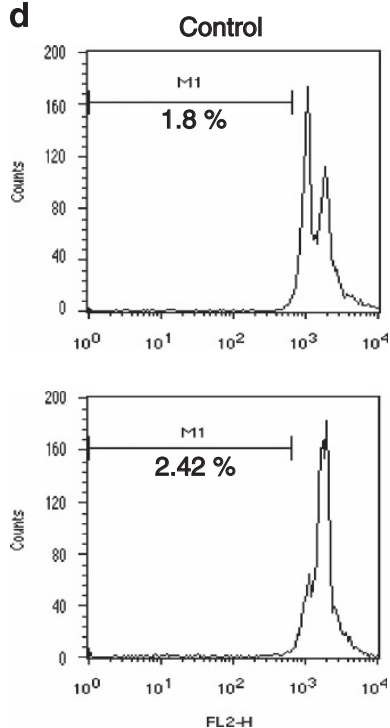

Bucillamine

+ Cisplatin
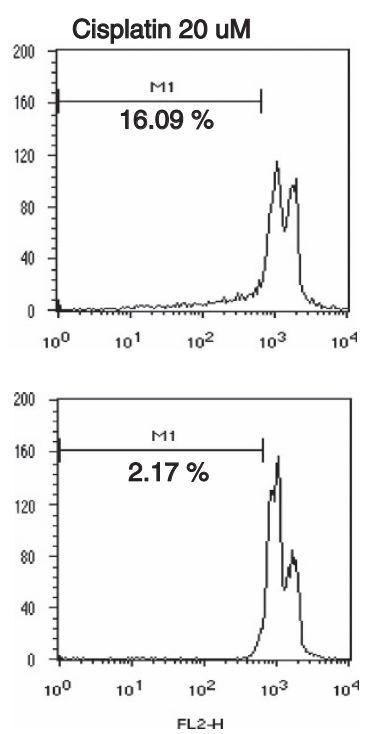

Bucillamine $2 \mathrm{mM}$

Figure 1 Pretreatment with bucillamine protects $\mathrm{HEI}-\mathrm{OCl}$ cells from cisplatin-induced apoptosis. (a) Cells were pretreated with various concentrations of bucillamine for $1 \mathrm{~h}$ followed by the addition of $20 \mu \mathrm{m}$ cisplatin for $30 \mathrm{~h}$, and cell viability was measured by MTT assays. (b) Genomic DNA isolated from cells, treated as indicated, was subject to $1.5 \%$ agarose gel electrophoresis. (c) Cells were stained with DAPI and observed under a fluorescence microscope to detect morphological changes in the nuclei. (d) Cells were treated with 2 mm bucillamine and the cell cycle was analyzed, according to sub- $\mathrm{G}_{0} / \mathrm{G}_{1}$ fraction ratio by flow cytometry. The results are shown as the mean \% (s.d.) of triplicate experiments. * Indicates a significant difference between cells treated with medium alone, cisplatin or cisplatin plus bucillamine $(P<0.01$ by one-way analysis of variance test).

apoptotic cell death, whereas pretreatment with bucillamine dose-dependently decreased the ladder pattern of DNA cleavage in cisplatin-treated HEI-OC1 cells. Also, morphological change of HEI-OC1 cells was examined after treatment with cisplatin in the presence or absence of $2 \mathrm{~mm}$ bucillamine (Figure 1c). DAPI staining showed the presence of apoptotic bodies in the nuclei of HEI-OC1 cells after treatment with cisplatin, but did not observ in cells maintained with either medium or bucillamine. Moreover, microscopic analysis showed that cisplatin-treated cells were variable in size, had protuberances that resulted in a spindle-like shape (indicated as an arrow). The cisplatin-treated cells were also shrunken, with their membranes rounded up, and they lost contact with either neighboring cells or the culture plate. However, pretreatment with bucillamine preserved cells to maintain normal morphology and their tightly attached form similar to control cells. To quantify the kinetics of both apoptotic events and cell cycle analysis, FACS analysis was performed with propidium iodide staining (Figure 1d). After treatment with cisplatin, the percentage of cells in the sub- $G_{0} / G_{1}$ phase increased up to $16.09 \%$ from $1.8 \%$ of control culture, whereas pretreatment with bucillamine markedly inhibited cisplatin-induced apoptotic cell death and reduced the percentage of cells in the sub- $\mathrm{G}_{0} / \mathrm{G}_{1}$ phase to $2.42 \%$. The percentage of cells in the sub- $G_{0} / G_{1}$ phase with $2 \mathrm{~mm}$ bucillamine-treated cells was $2.17 \%$. These results suggest that pretreatment with bucillamine prevented apoptotic cell death induced by cisplatin.

Bucillamine suppresses the activation of caspase- 3 and caspase-8 in cisplatin-treated HEI-OC1 cells.

We tested whether caspase- 3 was involved in cisplatin-induced apoptosis using a caspase-3 colorimetric assay (R\&D Systems). 
Treatment with cisplatin $(20 \mu \mathrm{M})$ significantly increased the catalytic activity of caspase-3 (4.14-fold compared with control, $P<0.01$ ), which was markedly decreased by bucillamine (2 mm) (Figure 2a). Bucillamine alone did not exert any significant effect on caspase- 3 activity. To analyze one of the upstream activators of caspase-3, the enzymatic activity of caspase- 8 was measured (Figure $2 \mathrm{~b}$ ). We found that treatment with cisplatin alone significantly increased caspase- 8 activity, whereas pretreatment with bucillamine markedly decreased the catalytic activity of caspase- 8 to the level similar to the control or bucillamine alone, suggesting that activities of both caspase3 and -8 are downregulated by bucillamine in the presence of cisplatin.

Next, caspase- 3 activation was examined microscopically by immunofluorescence at a single-cell level as well as by western blot analysis using an antibody specific for the activated form of caspase-3 (Figures $3 \mathrm{a}$ and b). Upon caspase-3 activation,

a

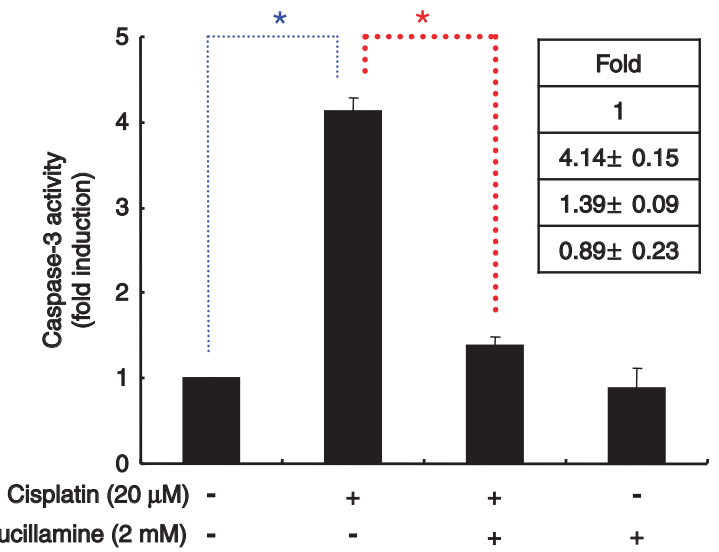

b

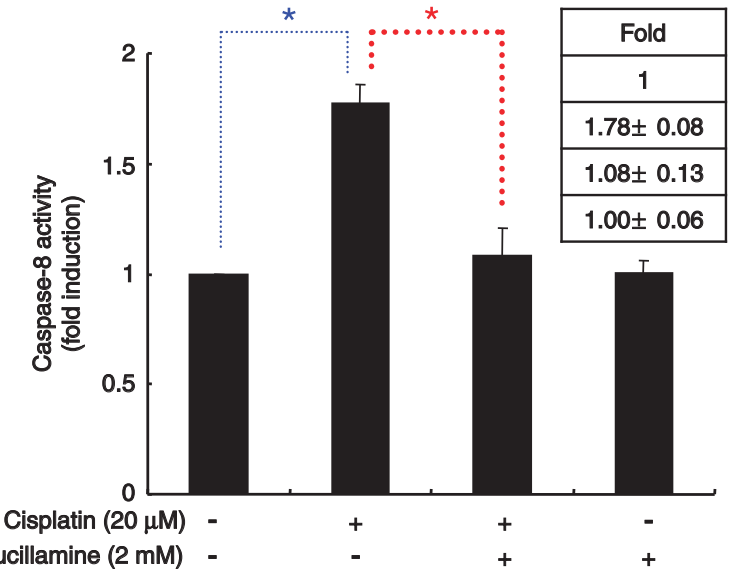

Figure 2 Bucillamine suppresses the catalytic activation of caspase- 3 and caspase- 8 in HEl-OC1 cells treated with cisplatin. Cells were pretreated with $2 \mathrm{~mm}$ bucillamine for $1 \mathrm{~h}$, followed by the addition of $20 \mu \mathrm{m}$ cisplatin for $24 \mathrm{~h}$. Cells lysates were reacted with Ac-IETD-pNA and Ac-DEVD-pNA, the p-NA-conjugated specific substrates for caspase-3 (a) and caspase-8 (b), respectively. Enzymatic activity assays for caspases were performed according to colorimetric assay at $405 \mathrm{~nm}$ absorbance using a spectrophotometer. Data are shown as the mean (s.d.) of triplicate experiments. ${ }^{*} P<0.01$ compared with control.
$32 \mathrm{kDa}$ procaspase is cleaved into $17 \mathrm{kDa}$ active form by proteolytic cleavage. ${ }^{34}$ Treatment of cells with cisplatin $(20 \mu \mathrm{M})$ for $24 \mathrm{~h}$ resulted in an increase of the fluorescent signal in the cytosol (Figure 3a) and appearance of $17 \mathrm{kDa}$ fragment detected by western blot (Figure 3b). In contrast, pretreatment with $2 \mathrm{~mm}$ bucillamine abolished the cisplatininduced activation of caspase-3.

\section{Bucillamine suppresses the generation of ROS and NO in cisplatin-treated HEI-OC1 cells.}

To analyze ROS-scavenging effects of bucillamine, we examined the intracellular ROS levels by flow cytometry by using an oxidation-sensitive fluorescent probe, DCF-DA, in HEI-OC1 cells (Figure 4a). The basal level of DCF-DA oxidation was observed in control cells, which was markedly suppressed by bucillamine $(2 \mathrm{~mm})$. To determine whether bucillamine suppresses ROS generation induced by cisplatin, intracellular levels of hydroxyl radicals and $\mathrm{NO}$ were measured using the fluorescent probes DCF-DA and 4-amino-5-methylamino$2^{\prime}, 7^{\prime}$-difluorofluorescein, respectively, (Figure $4 \mathrm{~b}$ ). The basal level of intracellular oxidant produced by HEI-OC1 cells was defined by a probe intensity of $10^{2}$ and bucillamine alone decreased hydroxyl radicals, shown as a fluorescent intensity of DCF, up to $34.6 \%$ and NO to $26.5 \%$ compared with the control (Figure 4c). However, treatment with cisplatin for $24 \mathrm{~h}$ markedly increased hydroxyl radicals up to $192.6 \%$ and NO up to $183.7 \%$ compared with control levels. In contrast, pretreatment with bucillamine for $1 \mathrm{~h}$ completely blocked the generation of hydroxyl radicals and NO by cisplatin.

\section{Bucillamine induces the expression and nuclear translocation of $\mathrm{Nrf} 2$}

Because Nrf2 is a key transcription factor in regulating the expression of phase II detoxifying and antioxidant genes, we first examined nuclear translocation of Nrf2 by immunofluorescence (Figure 5a). In the fluorescent microscopic view, Nrf2 was mainly located in cytosol, whereas treatment with cisplatin slightly increased nuclear Nrf2 compared with untreated controls. However, pretreatment with bucillamine markedly increased translocation of Nrf2 into the nucleus in the presence or absence of cisplatin. Western blot analysis of cytosolic and nuclear fractions clearly demonstrated that nuclear fraction of Nrf2 was time-dependently increased in expression by pretreatment with bucillamine in the presence of cisplatin (Figure 5b). As endogenous Nrf2 is mainly found in the cytoplasm under normal conditions, we did not find much effect on the cytoplasmic fraction of Nrf2 with either cisplatin or bucillamine treatment. Next, Nrf2 expression was tested by RT-PCR and quantitative real-time PCR. As shown in Figure $5 \mathrm{c}$ and $\mathrm{d}$, pretreatment with bucillamine resulted in a timedependent increase of the expression levels of Nrf2 mRNA.

\section{Bucillamine increases intracellular GSH level by inducting} GSH synthesis genes

Because bucillamine induces Nrf2 nuclear translocation (Figure 5), we examined whether expression of Nrf2 target 

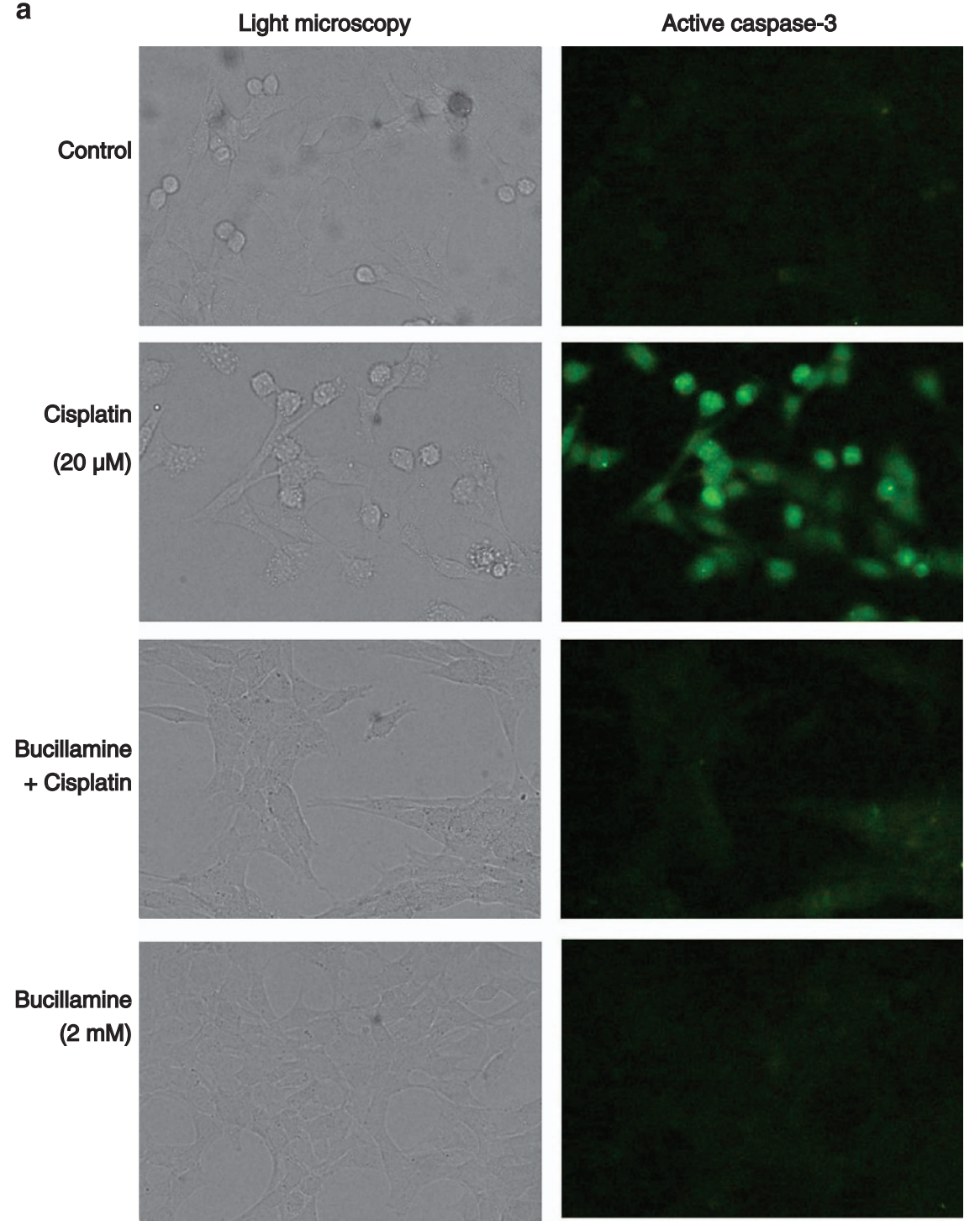

b

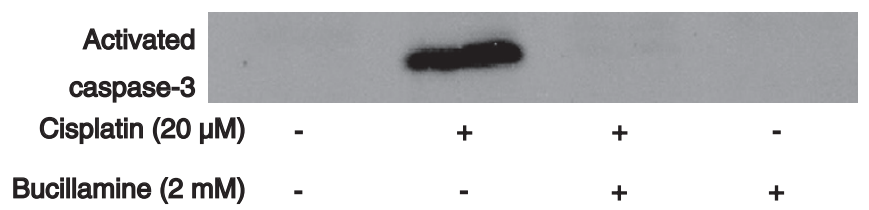

Figure 3 Bucillamine suppresses cisplatin-induced caspase-3 activation in HEI-OC1 cells. (a) Cells were pretreated with 2 mM bucillamine for $1 \mathrm{~h}$ followed by the addition of $20 \mu \mathrm{m}$ cisplatin for $24 \mathrm{~h}$. Cells were then washed and fixed, and the active form of caspase-3 was determined by immunofluorescence. Pictures were taken using a fluorescence microscope (original magnification, $\times 600$ ). (b) Equal amounts of total proteins $(50 \mu \mathrm{g}$ per lane) from cell lysate of the above experimental conditions were prepared, and subject to SDS-PAGE and western blot analyses.

genes related to redox regulation of the GSH system, including $\gamma$-GCS (GCLC and GCLM subunits; a rate-limiting enzyme of GSH synthesis) and GSS. Treatment with bucillamine significantly increased the expression of GCLC and modifier subunit (GCLM) compared with cisplatin-treated cells (Figures $6 a$ and $b$ ). However, bucillamine slightly increased mRNA levels of GSS compared with cisplatin-treated cells using RTPCR at the indicated time point and quantitative RT-PCR at $12 \mathrm{~h}$. Western blot analysis showed that bucillamine significantly increased the expression of GCLC, but not GSS and GCLM, after cisplatin treatment for $24 \mathrm{~h}$ (Figure 6c). We next examined whether pretreatment with bucillamine modulated the intracellular GSH contents in cisplatin-treated HEI-OC1 cells. GSH concentration in cisplatin-treated cells decreased from a control value of $26.03 \pm 1.34$ (mean \pm s.e.m., $n=6)$ to $16.47 \pm 1.36 \mathrm{nmol} \mathrm{mg}^{-1}$ protein $(n=6, P<0.01)$. Pretreatment with bucillamine prevented the depletion of GSH $\quad\left(36.34 \pm 1.15 \mathrm{nmol} \mathrm{mg}^{-1}\right.$ protein $) \quad(n=6, \quad P<0.01)$ 

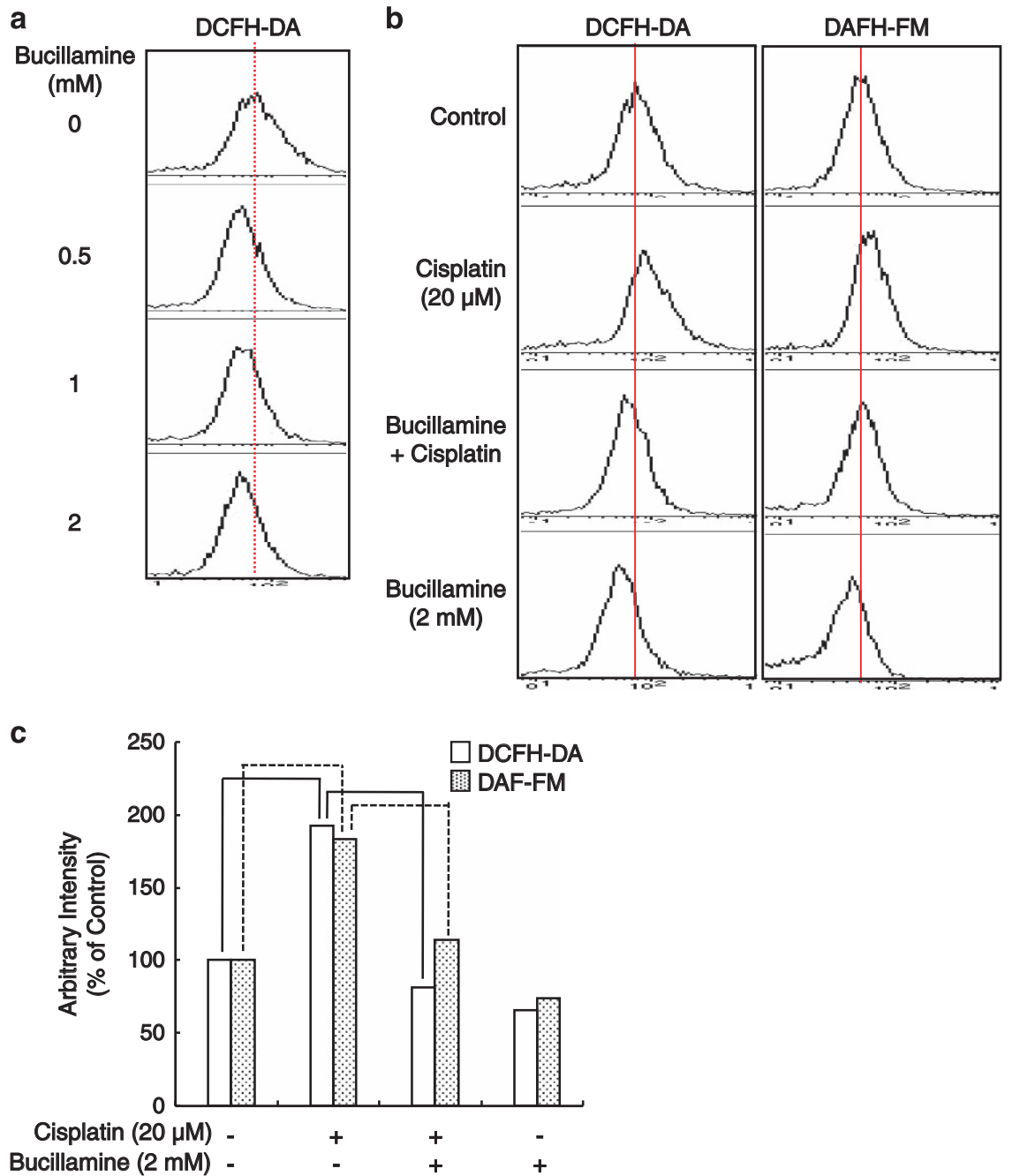

Figure 4 Bucillamine scavenges ROS generated by cisplatin in HEI-OC1 cells. (a) To test spontaneous production of intracellular ROS, cells were treated with DCF-DA, a ROS-specific fluorescence dye, for $1 \mathrm{~h}$ and then, fluorescence intensity was measured using a flow cytometer. (b) Cells were pretreated with $2 \mathrm{~mm}$ bucillamine followed by the addition of $20 \mu \mathrm{m}$ cisplatin for $24 \mathrm{~h}$. Then, cells were incubated with the dyes, including DCF-DA for hydroxyl radical and 4-amino-5-methylamino-2',7'-difluorofluorescein for nitric oxides. After $1 \mathrm{~h}$, the fluorescence intensity was measured using a flow cytometer. (c) Relative intensities from FACS analyses are shown in the bar graph.

compared with cells treated with cisplatin alone. Notably, bucillamine alone significantly increased intracellular GSH contents $\left(45.75 \pm 1.76 \mathrm{nmol} \mathrm{mg}^{-1}, n=6, P<0.01\right)$ compared with the control (Figure 6d). These results indicate that pretreatment with bucillamine significantly increased intracellular GSH contents by the induction of GSH synthesis genes via Nrf2 activation.

\section{Bucillamine induces expression of phase II detoxification enzymes in HEI-OC1 cells}

The transcription factor Nrf2, a major regulator of genes encoding phase II detoxifying enzymes, is essential in protecting cells from oxidative damage. We found that mRNA expression of antioxidant genes, including $\mathrm{HO}-1, \mathrm{Cu} / \mathrm{Zn}$ SOD1 and MnSOD2 significantly increased after pretreatment with bucillamine compared with cisplatin-treated cells at $12 \mathrm{~h}$ using quantitative RT-PCR analysis (Figure 7a). Interestingly, bucillamine alone also induced high mRNA levels of these genes. We also examined protein levels of HO-1, SOD1 and SOD2 enzymes in response to cisplatin treatment in the presence or absence of bucillamine at $24 \mathrm{~h}$. Consistent with mRNA expression, bucillamine markedly induced the expression of HO-1, SOD1 and SOD2 enzymes compared with cells treated with cisplatin alone. Bucillamine alone also significantly increased the protein levels of these enzymes (Figure $7 b$ ).

\section{siRNA knockdown of phase II HO-1 and SOD2 enzymes} does not attenuate the protective effects of bucillamine Because phase II enzymes, such as HO-1 and SOD2, are wellknown antioxidant enzymes, we determined whether knockdown of cytosolic HO-1 or mitochondrial SOD2 enzyme can regulate cisplatin-induced cell death and whether the protective effects of bucillamine against cisplatin is mediated by these enzymes. Transfection with siRNA HO-1 $(47.46 \%)$, siRNA SOD2 (45.47\%) and both (41.84\%) slightly increased the sensitivity of cytotoxicity in response to cisplatin compared 

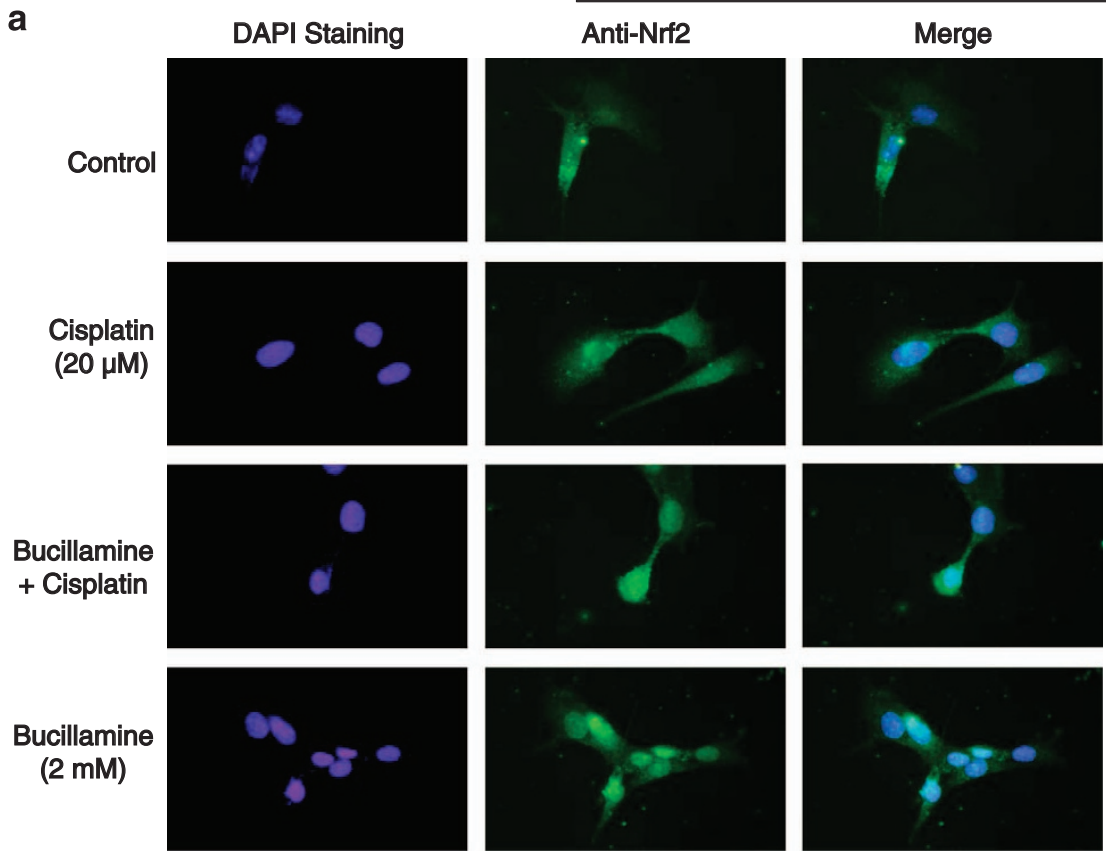

b

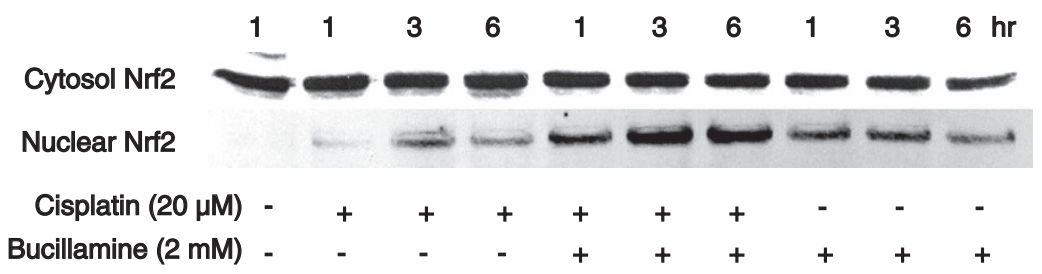

C

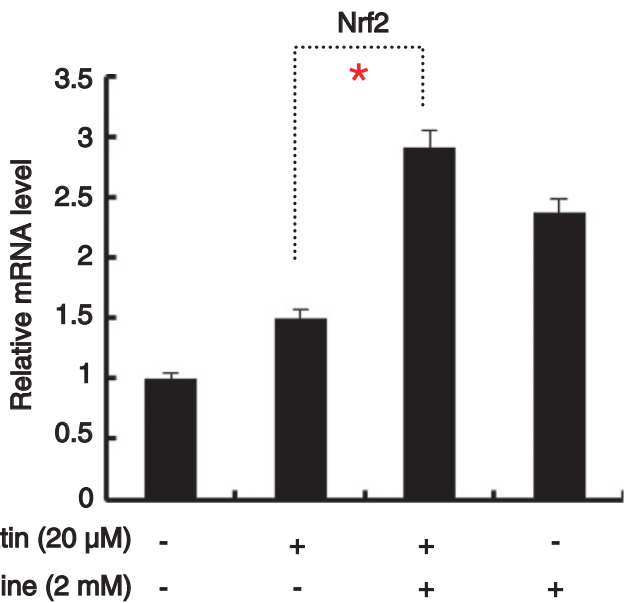

d

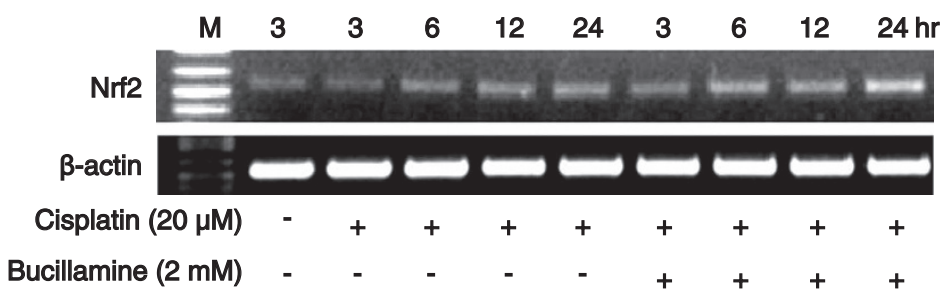

Figure 5 Bucillamine induces the subcellular localization of Nrf2 in HEl-OC1 cells treated with cisplatin. (a) Cells grown in chamber slides were pretreated with $2 \mathrm{~mm}$ bucillamine for $1 \mathrm{~h}$ followed by the addition of $20 \mu \mathrm{m}$ cisplatin for $12 \mathrm{~h}$. Subcellular localization of Nrf2 was detected by indirect immunofluorescence staining with anti-Nrf2 antibodies followed by Alexa488-conjugated second antibodies (green). The nucleus (left panel) was stained with DAPI (blue), and fluorescent images were obtained. (b) Cytosolic (CE) and nuclear (NE) extracts from cells were separated on $12 \%$ SDS-PAGE and subjected to western blot analysis using anti-Nrf2 antibody. (c) Quantitative real-time PCR was carried out to determine the relative expression level of Nrf2 at $3 \mathrm{~h}$. (d) Total RNA from cells was isolated with TRIzol reagent, cDNA was generated using reverse transcriptase, and PCR was performed to determine expression levels of Nrf2 at indicated time points. 


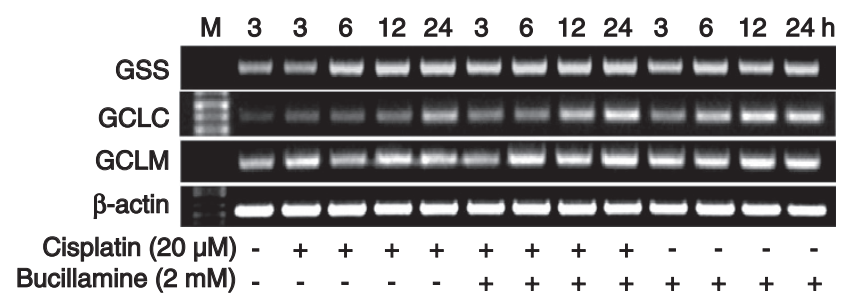

b

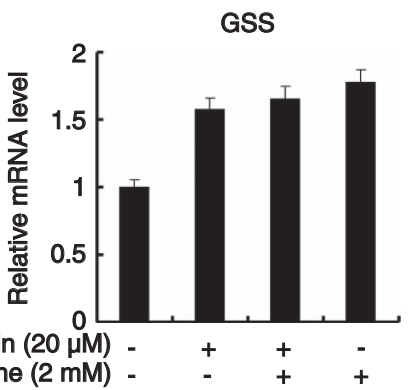

Bucillamine $(2 \mathrm{mM})-\quad+\quad+\quad+$
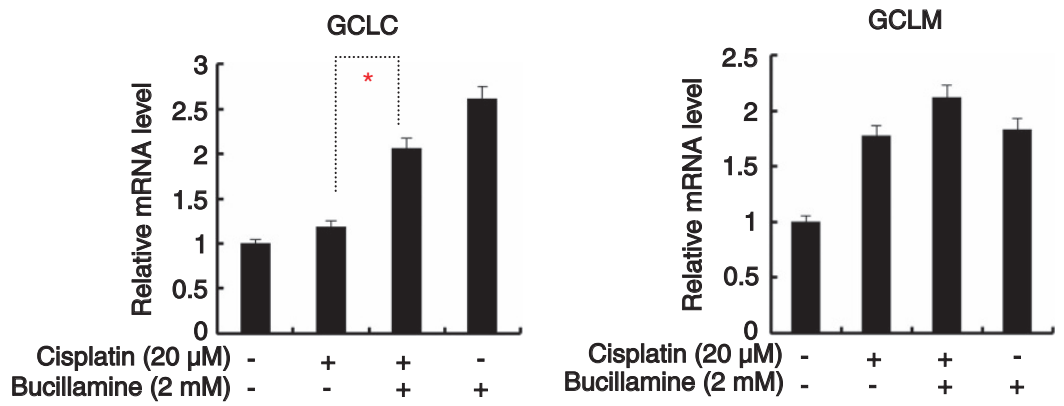

c

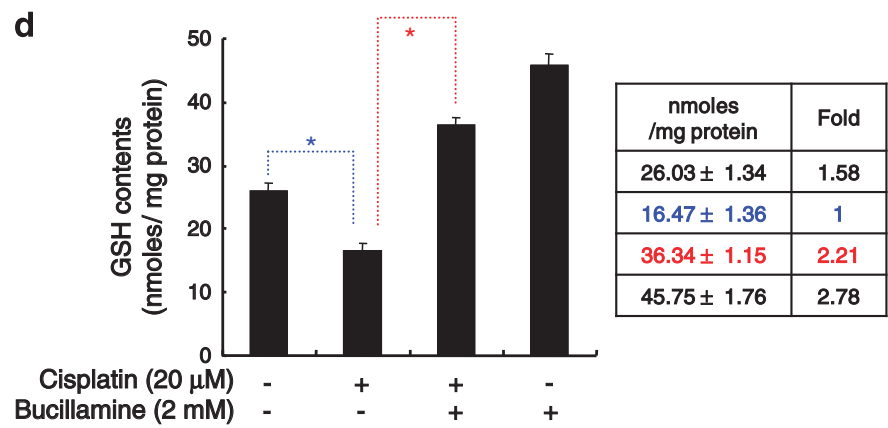

Figure 6 Bucillamine increases expression of $\gamma$-GCS and GSS in HEl-OC1 cells. (a) Cells were pretreated with $2 \mathrm{~mm}$ bucillamine for $1 \mathrm{~h}$ followed by the addition of $20 \mu \mathrm{m}$ cisplatin for different time intervals as indicated. Total RNA was isolated and cDNA was synthesized by reverse transcription. cDNAs of $\gamma$-glutamylcysteine synthetase ( $\gamma$-GCS: GCLC and GCLM) and glutathione synthetase (GSS) were amplified using specific primer sets. (b) mRNA expression levels of GSS, GCLC and GCLM were analyzed by quantitative real-time PCR at $12 \mathrm{~h}$. (c) Cell lysates were collected, electrophoresed through an SDS-polyacrylamide gel, and subject to immunoblot analysis with antibodies against $\gamma$-GCS (GCLC and GCLM) or GSS. The protein and mRNA levels of $\beta$-actin were used as controls. (d) Intracellular GSH content was measured by using a Glutathione Assay Kit. Total GSH contents were expressed as nmol $\mathrm{mg}^{-1}$ protein. Values are represented as the mean (s.d.) of triplicate samples. ${ }^{*} P<0.01$ compared with control.

with cells treated with cisplatin alone (54.34\%) and the control scramble siRNA (51.46\%) (Figure 8a). Pretreatment with bucillamine significantly recovered the protective effects against cisplatin in cells transfected with siRNA HO-1(79.22\%), siRNA SOD2 $(76.93 \%)$ or both $(69.31 \%)$, respectively (Figure $8 \mathrm{a})$. Therefore, we performed a western blot to determine whether knockdown of HO-1, SOD2 or both induces the catalytic activation of caspase-3 (Figure 8b). We found that knockdown of antioxidants HO-1, SOD2 or both weakly increased the active form of caspase-3 in cisplatin-treated HEI-OC1 cells, confirming the cell viability assay. In contrast, pretreatment with bucillamine significantly inhibited caspase-3 activation irrespective of knockdown of HO-1, SOD2 or both, indicating that bucillamine-mediated protective effects do not necessarily require the enzymatic activity of $\mathrm{HO}-1$ and SOD2 in response to cisplatin. 
a

HO-1
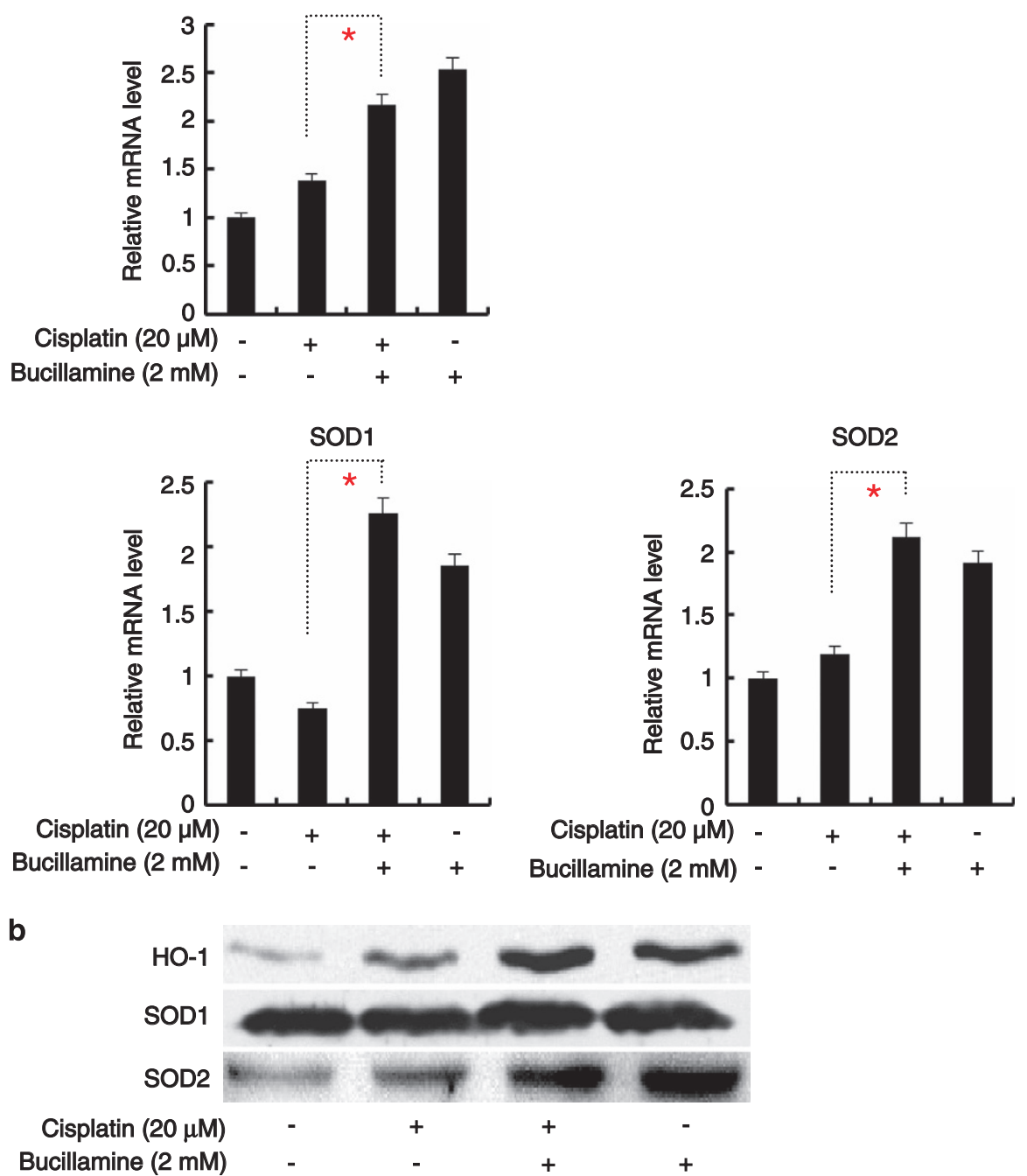

Figure 7 Bucillamine induces phase II antioxidants and detoxifying enzymes in HEl-OC1 cells treated with cisplatin. (a) Cells were pretreated with $2 \mathrm{~mm}$ bucillamine for $1 \mathrm{~h}$ followed by the addition of $20 \mu \mathrm{m}$ cisplatin at $12 \mathrm{~h}$. Phase II antioxidant genes (HO-1, SOD 1 and SOD2) from total RNA were amplified using specific primer sets. Expression levels of HO-1, SOD1 and SOD2 were significantly increased by the pretreatment with bucillamine as compared with cisplatin alone at $12 \mathrm{~h}$. (b) Cell lysates were electrophoresed through an SDS-polyacrylamide gel and subject to immunoblot analysis for HO-1, SOD1 and SOD2.

\section{Bucillamine prevents cisplatin-induced cell death and} hearing loss

To confirm the protective effects of bucillamine on sensory hair cells from the organ of Corti explants against cisplatin, cochlear explants of 2-day neonatal (P2) rats were isolated, dissected into three parts (apex, middle and basal) and cultured in 4-well plates. Cochlear explants treated with cisplatin in the presence or absence of $2 \mathrm{~mm}$ bucillamine were stained with Alexa 568-phalloidin to label the stereocilia of sensory hair cells. We found that cochlear cultures treated with cisplatin resulted in disorganized sensory hair cell rows and loss of stereocilia in the majority of sensory hair cells (Figure 9a). In contrast, bucillamine-pretreated cochlear cultures showed three orderly rows of OHCs and one row of inner hair cells, similar to control (not shown).
To determine the protective effects of bucillamine in vivo, we measured ABR thresholds in control mice (saline solution), mice injected with cisplatin $\left(16 \mathrm{mg} \mathrm{kg}^{-1}\right.$ per 4 days $)$ in the presence or absence of bucillamine, and mice injected with bucillamine alone ( $400 \mathrm{mg} \mathrm{kg}^{-1}$ per 4 days) (Figure $9 \mathrm{~b}$ and c). For 3 days following cisplatin exposure, ABR thresholds increased significantly in all frequencies $(2,4,8,16$ and $32 \mathrm{kHz}$ tones and click), and the changes of each values were statistically significant compared with the control group $(P<0.05)$. The increase in ABR thresholds was greater for the higher-frequency stimuli at 16 and $32 \mathrm{kHz}$ than at 4 and $8 \mathrm{kHz}$. In contrast, pretreatment with bucillamine plus cisplatin did not show significant ABR threshold changes compared with the saline-treated control group. Importantly, ABR thresholds in the bucillamine plus cisplatin-treated group were 

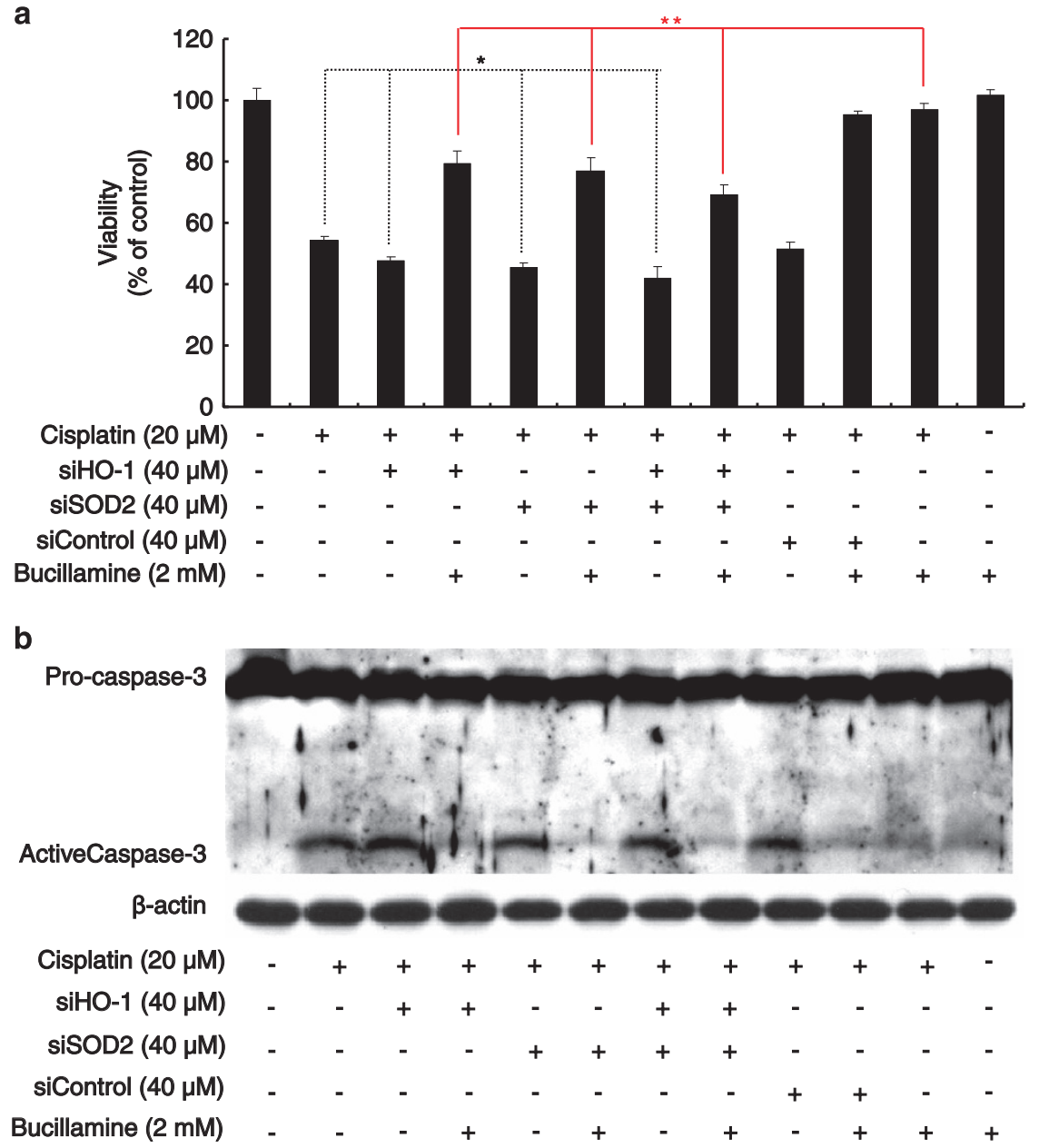

Figure 8 siRNA knockdown of HO-1 and SOD2 enzymes does not completely block the protective effects of bucillamine. (a) After transfection of $\mathrm{HEI}-\mathrm{OC} 1$ cell with double-stranded siRNA (HO-1, SOD2 or both), cells were pretreated with various concentrations of bucillamine for $1 \mathrm{~h}$ followed by the addition of $20 \mu \mathrm{m}$ cisplatin for $24 \mathrm{~h}$. Then, cell viability was measured by MTT assays. (b) Cell lysates were subject to immunoblot analysis with antibodies against pro-caspase-3 and active form of caspase-3. $\beta$-actin was used as a control.

significantly lower than those in the cisplatin alone $(P<0.01)$. ABR thresholds in bucillamine-alone were similar to those in control with slightly lower values at $8 \mathrm{kHz}$ and click $(P<0.01)$. These results indicate that bucillamine ameliorates cisplatininduced hair cell loss ex vivo as well as hearing impairments in vivo.

\section{DISCUSSION}

Cisplatin is an effective chemotherapeutic agent that is currently used as the standard treatment for a variety of human malignant neoplasms. However, clinical application of cisplatin is limited because it often induces serious and irreversible toxicity in bone marrow, gastrointestinal tract, kidney, cochlear and nervous system. ${ }^{2,3}$ Previous studies using thiol-containing compounds, including diethyldithiocarbamate, GSH, lipoic acid, sodium thiosulfate and 4-methylthiobenzoic acid, have evaluated the protective effects of these compounds against the adverse effects of cisplatin.,20,35 Additionally, the T-type calcium channel blocker flunarizine and selenium-containing compound ebselen have shown protective effects against cisplatin-induced cytotoxicity and ototoxicity. ${ }^{19,21}$ However, the mechanisms of cisplatin ototoxicity are yet to be fully understood.

In this study, we examined whether bucillamine has a protective effect against cisplatin. Pretreatment with bucillamine markedly suppressed apoptotic cell death in cisplatintreated HEI-OC1 cells. In particular, bucillamine prevented cisplatin-induced damages, including morphological changes, MTT reduction, DNA laddering and nuclear fragmentation, and decrease in the percentage of cells in the sub- $G_{0} / G_{1}$ phase in a dose-dependent manner. Therefore, we demonstrate for the first time that bucillamine can reduce cisplatininduced hair cell toxicity in auditory cells and the organ of Corti. In addition, we also present in vivo evidence that bucillamine prevents ABR threshold shifts induced by cisplatin in Balb/C mice.

A number of studies suggest that caspase activation triggers the apoptotic process in various types of cells. Caspase- 3 , an apoptosis executioner, plays a pivotal role especially in the terminal phase of apoptosis and is activated by other caspases, 


\section{a}
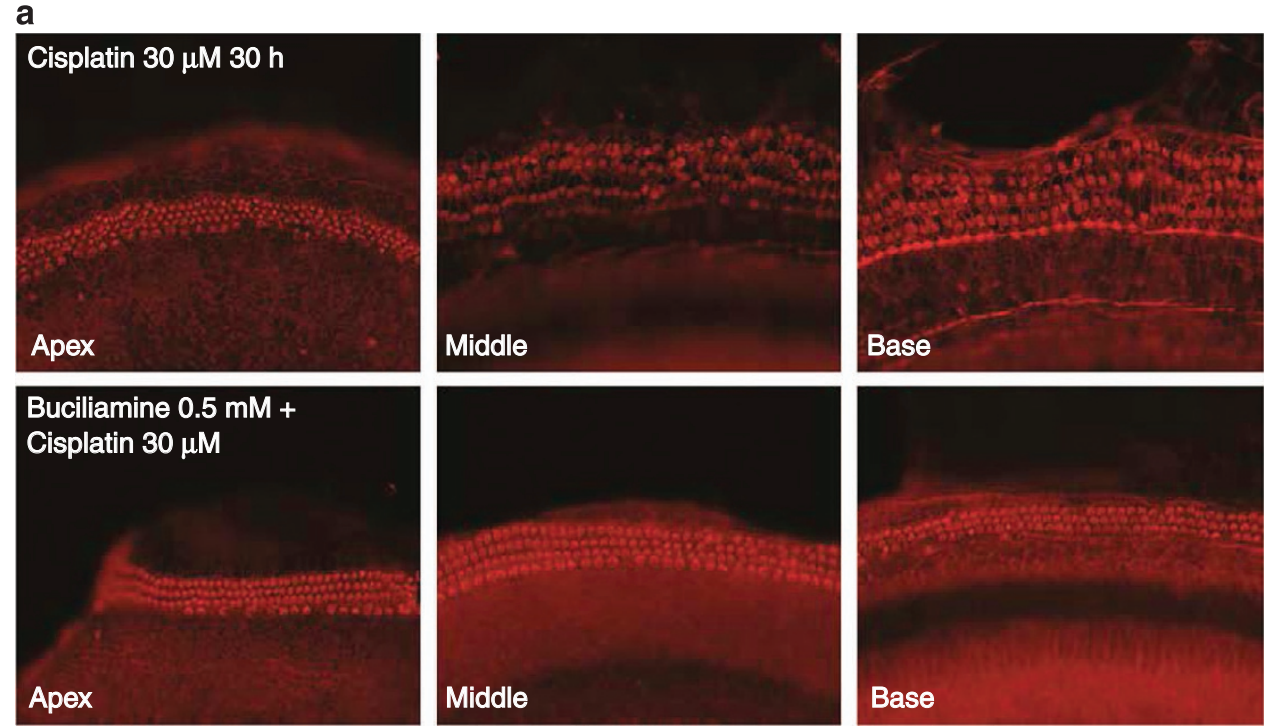

b

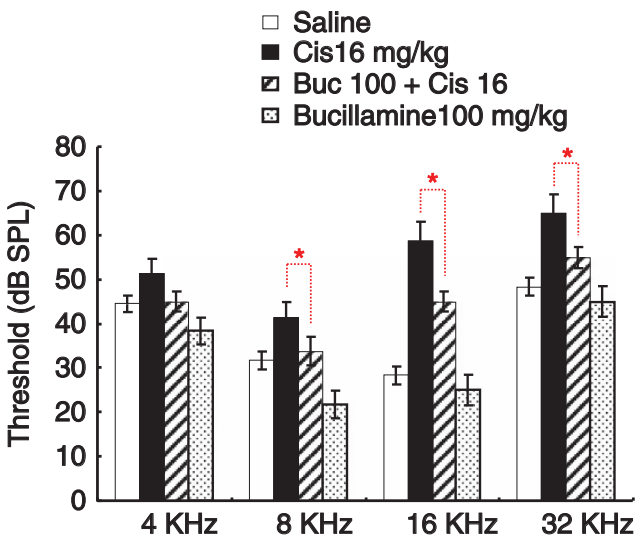

C

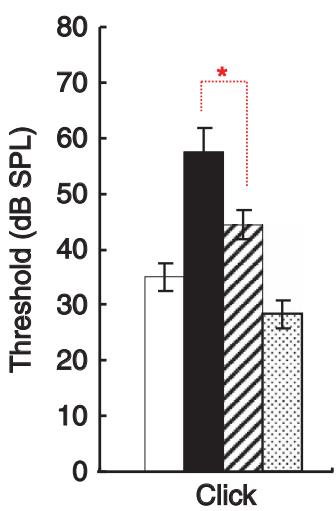

Figure 9 Bucillamine protects sensory hair cells from cisplatin in rat primary organ of Corti explants and prevents hearing loss in adult mice. (a) Organ of Corti explants were dissected into three parts—basal, middle and apex turns-and treated with $20 \mu \mathrm{m}$ cisplatin alone, $2 \mathrm{~mm}$ bucillamine or cisplatin for $30 \mathrm{~h}$. Cultures were stained with tetramethylrhodamine isothiocyanate-conjugated phalloidin and then observed under a fluorescence microscope. (b) Auditory-brainstem-evoked response (ABR) thresholds were measured 3 days after i.p. injection of cisplatin only (back bar, $n=5$ ), cisplatin plus bucillamine (hatch bar, $n=5$ ), bucillamine only (dot bar, $n=5$ ) and control (saline) only (white bar, $n=5$ ). (c) Click thresholds were measured using the same mice groups in (b). ABR threshold changes were compared with the basal level in the control mice injected with saline. Values are shown as the mean \pm s.e.m. * Indicates significant $(P<0.05)$ compared with the control (saline) group.

such as caspase- 8 and caspase- $9 .{ }^{36}$ Activated caspase- 3 is important for the occurrence of morphological changes, such as DNA laddering and nuclear fragmentation in apoptotic cells. ${ }^{37}$ Caspase- 8 activity is initiated when FAS ligand or tumor necrosis factors bind to cell-surface receptors that contain a death domain, and lies upstream of caspase- $3 .{ }^{38}$ Several reports have demonstrated that cisplatin induced caspase- 3 activation in HEI-OC1 cells, ${ }^{39-41}$ which was virtually suppressed by co-treating with various compounds, such as NF- $\mathrm{\kappa B}$ inhibitors (Bay 11-7085 and SN-50), polyphenolic compounds (epicatechin) and immunosuppressors (JWH-015 and HU210). A recent study showed that luteolin, acting as antioxidant and anti-inflammatory reagent, suppressed activation of caspase- 3 , caspase- 8 and caspase- 9 , and protects cisplatin-induced apoptosis in auditory cells. ${ }^{39}$ In this study, we showed that cisplatin significantly increased the active form of caspase- 3 and the activities of caspase- 3 and -8 in auditory cells, which was significantly inhibited by bucillamine pretreatment, suggesting that bucillamine effectively suppresses cisplatin-induced cell death.

Like other cysteine derivatives, bucillamine is able to rapidly enter into cells and interrupt redox signaling and oxidative injury. Mazor et al. $^{42}$ demonstrated that the antioxidant capacity of bucillamine is higher than that of Trolox, ascorbic acid or the thiol antioxidants GSH and NAC. In addition, Horwitz and Sherman ${ }^{30}$ reported that bucillamine prevents damages from peroxide or superoxide radicals in cultured adult rat cardiac myocytes and substantially reduces myocardial infarct size when administered during reperfusion. In rheumatoid arthritis patients, the antioxidant defense system is found to be compromised, in which the activities of GSH peroxidase and catalases, as well as the plasma concentrations of 
$\beta$-carotene, vitamin $\mathrm{E}$ and reduced $\mathrm{GSH}$, are significantly decreased compared with those in healthy controls. ${ }^{43,44}$ In addition, several reports showed that cisplatin exerts its renal and cochlear toxicity by generating ROS and interfering with the antioxidant defense system. Accordingly, thiol-containing compounds (for example, diethyldithiocarbamate, GSH and NAC) and the antioxidant enzymes (for example, catalase and SOD) have been found to be nephroprotective and otoprotective against cisplatin-induced GSH depletion and GSH peroxidase inactivation in cochlear tissues. ${ }^{3,14,45}$ In this study, we showed that the protective effects of bucillamine against cisplatin were achieved through the reduction of free radicals, including hydroxyl radicals, NOs and superoxide anions, indicating that bucillamine acts as a potent antioxidant against cisplatin-induced ROS and reactive nitrogen species in auditory cells.

The transcription factor Nrf2 binds antioxidant response elements and regulates phase II detoxifying and antioxidant genes. ${ }^{46}$ A recent study has demonstrated that bucillamine induces GSH biosynthesis via Nrf2 activation in murine Hepa1-6 and human HepG2 hepatoblastoma cells where the GCLC, the rate-limiting enzyme of GSH biosynthesis and the multidrug-resistance-associated protein (Mrp2) were induced by Nrf2. ${ }^{33}$ We found that knockdown of HO-1 and SOD2 weakly increased cytotoxicity in cisplatin-induced cells compared with cisplatin-alone-treated cells. However, western blot analysis indicates that active caspase- 3 levels were not increased in cells transfected with siHO-1, siSOD2 or both, compared with cisplatin alone. Although Nrf2 activation by bucillamine induces HO-1 and SOD2 expression, these antioxidant enzymes may have a partial role in bucillamine-mediated protective effects.

GSH acts as a free radical scavenger, and intracellular GSH participates in the metabolism and detoxification of electrophilic drugs, antioxidant defense, maintenance of thiol redox status and modulation of cell proliferation. ${ }^{47}$ In the present study, we demonstrated that bucillamine significantly induces the GSH synthesis enzymes, including $\gamma$-GCS subunits (GCLC and GCLM) and GSS, via Nrf2 transactivation, which then results in the increase of intracellular GSH contents in auditory cells. Therefore, our study suggests that bucillamine possesses excellent antioxidant properties in vitro, which may render the compound suitable for therapeutic use in diseases resulting from oxidative damages.

Ex vivo culture of the organ of Corti has been a useful model for studying cisplatin- or aminoglycoside-induced toxicity and otoprotective molecule screening. ${ }^{7}$ In the inner ear, cisplatin application causes sensorineural hearing loss through apoptosis of the cochlear hair cells and the spiral ganglion neurons. ${ }^{48}$ The most prominent change observed in the cochlea after cisplatin administration consists of loss of $\mathrm{OHCs}$ which progresses from basal to apex in the cochlea turn. Cisplatin ototoxicity is not limited to the auditory hair cells but also affects the auditory neuron, the stria vascularis and the supporting cells of the organ of Corti. ${ }^{49,50}$ In particular, supporting cells (Deiter's cells) appeared more sensitive than OHCs, and structural malformation of the supporting cell preceded detectable changes in OHCs. ${ }^{51}$ Several studies with thiol-containing antioxidants, such as NAC, GSH ester, diethyldithiocarbamate, lipoic acid and sodium thiosulfate, have proposed the advantages of otoprotective agents to reduce the adverse effects of cisplatin on auditory functions. ${ }^{7,52-54}$ In the current study, we tested the otoprotective role of bucillamine in cisplatin-treated $\mathrm{Balb} / \mathrm{C}$ mice, and found that bucillamine protects against cisplatin-induced ototoxicity, which was evidenced by reducing ABR threshold shifts at all frequencies. Several reports demonstrated that a variety of antioxidant agents, including D-methionine, ${ }^{55}$ NAC, ${ }^{56}$ sodium thiosulfate, ${ }^{57}$ thiourea, ${ }^{58}$ diethyldithiocarbamate ${ }^{8}$ and 4-methylthiobenzoic acid, ${ }^{8}$ significantly inhibited acute cochlear ototoxicity and markedly reduced ABR thresholds in cisplatin-treated animals. Additionally, ebselen pretreatment eliminated ABR threshold shift and significantly reduced the pathologic consequences upon cisplatin treatment $t^{8,19,52,59}$ and noise exposure ${ }^{60,61}$ in animals.

In the current study, we first investigated the anti-apoptotic, antioxidant and otoprotective effects of bucillamine administered with cisplatin in HEI-OC1 cells in cultured organ of Corti and mice in vivo. Because ototoxicity and cytotoxicity caused by cisplatin is mainly dependent on the depletion of intracellular antioxidants in auditory cells and the cochlea, our results strongly suggest that bucillamine possesses scavenging, antioxidant and anti-inflammatory effects through elimination of free radicals, induction of antioxidant enzymes and increase in intracellular GSH content. Therefore, our results together with currently available information on the pharmacological application of bucillamine, suggest that bucillamine might be a potential agent in prevention of hearing loss caused by insults of ROS challenges.

\section{CONFLICT OF INTEREST}

The authors declare no conflicts of interest.

\section{ACKNOWLEDGEMENTS}

This work was supported by the National Research Foundation of Korea [NRF] grant funded by the Korea government [MSIP] [No. 2011-0028866] and [No, 2011-0030130].

1 Fausti SA, Henry JA, Schaffer HI, Olson DJ, Frey RH, Bagby GC Jr. High-frequency monitoring for early detection of cisplatin ototoxicity. Arch Otolaryngol Head Neck Surg 1993; 119: 661-666.

2 Hamers FP, Brakkee JH, Cavalletti E, Tedeschi M, Marmonti L, Pezzoni G et al. Reduced glutathione protects against cisplatin-induced neurotoxicity in rats. Cancer Res 1993; 53: 544-549.

3 Rybak LP, Ravi R, Somani SM. Mechanism of protection by diethyldithiocarbamate against cisplatin ototoxicity: antioxidant system. Fundamental and Applied Toxicology 1995; 26: 293-300.

4 Laurell G, Bagger-Sjoback D. Degeneration of the Organ of Corti following intravenous administration of cisplatin. Acta Otolaryngol 1991; 111: 891-898.

5 Schweitzer VG. Cisplatin-induced ototoxicity: the effect of pigmentation and inhibitory agents. Laryngoscope 1993; 103: 1-52.

6 Hinojosa R, Riggs LC, Strauss M, Matz GJ. Temporal bone histopathology of cisplatin ototoxicity. Am J Otol 1995; 16: 731-740. 
7 Kopke RD, Liu W, Gabaizadeh R, Jacono A, Feghali J, Spray D et al. Use of organotypic cultures of Corti's organ to study the protective effects of antioxidant molecules on cisplatin-induced damage of auditory hair cells. Am J Otol 1997; 18: 559-571.

8 Kamimura T, Whitworth CA, Rybak LP. Effect of 4-methylthiobenzoic acid on cisplatin-induced ototoxicity in the rat. Hear Res 1999; 131: 117-127.

9 Jamieson ER, Lippard SJ. Structure, recognition, and processing of cisplatin-DNA adducts. Chem Rev 1999; 99: 2467-2498.

10 McKeage MJ. Comparative adverse effect profiles of platinum drugs. Drug Saf 1995; 13: 228-244.

11 Clerici WJ, DiMartino DL, Prasad MR. Direct effects of reactive oxygen species on cochlear outer hair cell shape in vitro. Hear Res 1995; 84: 30-40.

12 Rybak LP, Whitworth C, Somani S. Application of antioxidants and other agents to prevent cisplatin ototoxicity. Laryngoscope 1999; 109: 1740-1744.

13 Watanabe KI, Hess A, Bloch W, Michel O. Nitric oxide synthase inhibitor suppresses the ototoxic side effect of cisplatin in guinea pigs. Anticancer Drugs 2000; 11: 401-406.

14 Ravi R, Somani SM, Rybak LP. Mechanism of cisplatin ototoxicity: antioxidant system. Pharmacol Toxicol 1995; 76: 386-394.

15 Freeman BA, Crapo JD. Biology of disease: free radicals and tissue injury. Lab Invest 1982; 47: 412-426.

16 Goldstein JC, Waterhouse NJ, Juin P, Evan GI, Green DR. The coordinate release of cytochrome $\mathrm{C}$ during apoptosis is rapid, complete and kinetically invariant. Nat Cell Biol 2000; 2: 156-162.

17 Babu E, Ebrahim AS, Chandramohan N, Sakthisekaran D. Rehabilitating role of glutathione ester on cisplatin induced nephrotoxicity. Ren fail 1999; 21: 209-217.

18 Jones MM, Basinger MA, Holscher MA. Control of the nephrotoxicity of cisplatin by clinically used sulfur-containing compounds. Fundam Appl Toxicol 1992; 18: 181-188.

19 Kim SJ, Park C, Han AL, Youn MJ, Lee JH, Kim Y et al. Ebselen attenuates cisplatin-induced ROS generation through Nrf2 activation in auditory cells. Hear Res 2009; 251: 70-82.

20 Markman M, D'Acquisto R, lannotti N, Kris M, Hakes T, Bajorin D et al. Phase-1 trial of high-dose intravenous cisplatin with simultaneous intravenous sodium thiosulfate. J Cancer Res Clini Oncol 1991; 117: 151-155.

21 So HS, Kim HJ, Lee JH, Lee JH, Park SY, Park C et al. Flunarizine induces Nrf2-mediated transcriptional activation of heme oxygenase-1 in protection of auditory cells from cisplatin. Cell Death Differ 2006; 13: 1763-1775.

22 el Barbary A, Altschuler RA, Schacht J. Glutathione S-transferases in the Organ of Corti of the rat: enzymatic activity, subunit composition and immunohistochemical localization. Hear Res 1993; 71: 80-90.

23 Pierson MG, Gray BH. Superoxide dismutase activity in the cochlea. Hear Res 1982; 6: 141-151.

24 Sies $\mathrm{H}$, Masumoto $\mathrm{H}$. Ebselen as a glutathione peroxidase mimic and as a scavenger of peroxynitrite. Adv Pharmacol 1997; 38: 229-246.

25 Itoh K, Wakabayashi N, Katoh Y, Ishii T, O'Connor T, Yamamoto M. Keap1 regulates both cytoplasmic-nuclear shuttling and degradation of Nrf2 in response to electrophiles. Genes Cells 2003; 8: 379-391.

26 Wakabayashi N, Dinkova-Kostova AT, Holtzclaw WD, Kang MI, Kobayashi A, Yamamoto $\mathrm{M}$ et al. Protection against electrophile and oxidant stress by induction of the phase 2 response: fate of cysteines of the Keap1 sensor modified by inducers. Proc Natl Acad Sci USA 2004; 101: 2040-2045

27 Wasserman WW, Fahl WE. Functional antioxidant responsive elements. Proc Natl Acad Sci USA 1997; 94: 5361-5366.

28 Morales A, Garcia-Ruiz C, Miranda M, Mari M, Colell A, Ardite E et al. Tumor necrosis factor increases hepatocellular glutathione by transcriptional regulation of the heavy subunit chain of gamma-glutamylcysteine synthetase. J Biol Chem 1997; 272: 30371-30379.

29 Matsuno H, Sugiyama E, Muraguchi A, Nezuka T, Kubo T, Matsuura K et al. Pharmacological effects of SA96 (bucillamine) and its metabolites as immunomodulating drugs-the disulfide structure of SA-96 metabolites plays a critical role in the pharmacological action of the drug. Int $J$ Immunopharmacol 1998; 20: 295-304.

30 Horwitz LD, Sherman NA. Bucillamine prevents myocardial reperfusion injury. J Cardiovasc Pharmacol 2001; 38: 859-867.

31 Whitekus MJ, Li N, Zhang M, Wang M, Horwitz MA, Nelson SK et al. Thiol antioxidants inhibit the adjuvant effects of aerosolized diesel exhaust particles in a murine model for ovalbumin sensitization. J Immunol 2002; 168: 2560-2567.
32 Amersi F, Nelson SK, Shen XD, Kato H, Melinek J, Kupiec-Weglinski JW et al. Bucillamine, a thiol antioxidant, prevents transplantation-associated reperfusion injury. Proc Natl Acad Sci USA 2002; 99: 8915-8920.

33 Wielandt AM, Vollrath V, Farias M, Chianale J. Bucillamine induces glutathione biosynthesis via activation of the transcription factor Nrf2. Biochem Pharmacol 2006; 72: 455-462.

34 Xanthoudakis S, Roy S, Rasper D, Hennessey T, Aubin Y, Cassady R et al. Hsp60 accelerates the maturation of pro-caspase-3 by upstream activator proteases during apoptosis. EMBO J 1999; 18: 2049-2056.

35 Rybak LP, Husain K, Evenson L, Morris C, Whitworth C, Somani SM. Protection by 4-methylthiobenzoic acid against cisplatin-induced ototoxicity: antioxidant system. Pharmacol Toxicol 1997; 81: 173-179.

36 Salvesen GS, Duckett CS. IAP proteins: blocking the road to death's door. Nat Rev Mol Cell Biol 2002; 3: 401-410.

37 Krieser RJ, Eastman A. Cleavage and nuclear translocation of the caspase 3 substrate Rho GDP-dissociation inhibitor, D4-GDI, during apoptosis. Cell Death Differ 1999; 6: 412-419.

$38 \mathrm{Hsu} \mathrm{H}$, Xiong J, Goeddel DV. The TNF receptor 1-associated protein TRADD signals cell death and NF-kappa B activation. Cell 1995; 81: 495-504.

39 Choi BM, Lim DW, Lee JA, Gao SS, Kwon DY, Kim BR. Luteolin suppresses cisplatin-induced apoptosis in auditory cells: possible mediation through induction of heme oxygenase-1 expression. J Med Food 2008; 11: 230-236.

40 Devarajan P, Savoca M, Castaneda MP, Park MS, Esteban-Cruciani N, Kalinec $\mathrm{G}$ et al. Cisplatin-induced apoptosis in auditory cells: role of death receptor and mitochondrial pathways. Hear Res 2002; 174: 45-54.

41 Jeong HJ, Kim SJ, Moon PD, Kim NH, Kim JS, Park RK et al. Antiapoptotic mechanism of cannabinoid receptor 2 agonist on cisplatin-induced apoptosis in the HEI-OC1 auditory cell line. J Neurosci Res 2007; 85: 896-905.

42 Mazor D, Greenberg L, Shamir D, Meyerstein D, Meyerstein N. Antioxidant properties of bucillamine: possible mode of action. Biochem Biophys Res Commun 2006; 349: 1171-1175.

43 Jaswal S, Mehta HC, Sood AK, Kaur J. Antioxidant status in rheumatoid arthritis and role of antioxidant therapy. Clin Chim Acta 2003; 338 : 123-129.

44 Kamanli A, Naziroglu M, Aydilek N, Hacievliyagil C. Plasma lipid peroxidation and antioxidant levels in patients with rheumatoid arthritis. Cell Biochem Funct 2004; 22: 53-57.

45 Sugihara K, Nakano S, Koda M, Tanaka K, Fukuishi N, Gemba M. Stimulatory effect of cisplatin on production of lipid peroxidation in renal tissues. Jpn J Pharmacol 1987; 43: 247-252.

46 Sakurai T, Kanayama M, Shibata T, Itoh K, Kobayashi A, Yamamoto M et al. Ebselen, a seleno-organic antioxidant, as an electrophile. Chem Res Toxicol 2006; 19: 1196-1204.

47 Ceconi C, Curello S, Cargnoni A, Ferrari R, Albertini A, Visioli O. The role of glutathione status in the protection against ischaemic and reperfusion damage: effects of N-acetyl cysteine. J Mol Cell Cardiol 1988; 20: 5-13.

48 Feghali JG, Liu W, Van De Water TR. L-n-acetyl-cysteine protection against cisplatin-induced auditory neuronal and hair cell toxicity. Laryngoscope 2001; 111: 1147-1155.

49 Anniko M, Sobin A. Cisplatin: evaluation of its ototoxic potential. Am J Otolaryngol 1986; 7: 276-293.

50 Weatherly RA, Owens JJ, Catlin FI, Mahoney DH. cis-platinum ototoxicity in children. Laryngoscope 1991; 101: 917-924.

51 Ramirez-Camacho R, Garcia-Berrocal JR, Trinidad A, Gonzalez-Garcia JA Verdaguer JM, Ibanez A et al. Central role of supporting cells in cochlear homeostasis and pathology. Med Hypotheses 2006; 67: 550-555.

52 Lynch ED, Gu R, Pierce C, Kil J. Reduction of acute cisplatin ototoxicity and nephrotoxicity in rats by oral administration of allopurinol and ebselen. Hear Res 2005; 201: 81-89.

53 Rybak LP, Husain K, Whitworth C, Somani SM. Dose dependent protection by lipoic acid against cisplatin-induced ototoxicity in rats: antioxidant defense system. Toxicol Sci 1999; 47: 195-202.

54 Rybak LP, Whitworth CA. Ototoxicity: therapeutic opportunities. Drug Discov Today 2005; 10: 1313-1321.

55 Campbell KC, Meech RP, Rybak LP, Hughes LF. The effect of D-methionine on cochlear oxidative state with and without cisplatin administration: mechanisms of otoprotection. J Am Acad Audiol 2003; 14: 144-156.

56 Thomas Dickey D, Muldoon LL, Kraemer DF, Neuwelt EA. Protection against cisplatin-induced ototoxicity by $\mathrm{N}$-acetylcysteine in a rat model. Hear Res 2004; 193: 25-30.

57 Leitao DJ, Blakley BW. Quantification of sodium thiosulphate protection on cisplatin-induced toxicities. J Otolaryngol 2003; 32: 146-150. 
58 Ekborn A, Laurell G, Ehrsson H, Miller J. Intracochlear administration of thiourea protects against cisplatin-induced outer hair cell loss in the guinea pig. Hear Res 2003; 181: 109-115.

59 Rybak LP, Husain K, Morris C, Whitworth C, Somani S. Effect of protective agents against cisplatin ototoxicity. Am J Otol 2000; 21: 513-520.

60 Kil J, Pierce C, Tran H, Gu R, Lynch ED. Ebselen treatment reduces noise induced hearing loss via the mimicry and induction of glutathione peroxidase. Hear Res 2007; 226: 44-51.

61 Lynch ED, Gu R, Pierce C, Kil J. Ebselen-mediated protection from single and repeated noise exposure in rat. Laryngoscope 2004; 114 333-337. (c) (1) $(\Theta)$ This work is licensed under a Creative Commons Attribution-NonCommercial-NoDerivs 3.0 Unported License. The images or other third party material in this article are included in the article's Creative Commons license, unless indicated otherwise in the credit line; if the material is not included under the Creative Commons license, users will need to obtain permission from the license holder to reproduce the material. To view a copy of this license, visit http://creativecommons.org/licenses/by-nc-nd/3.0/ 